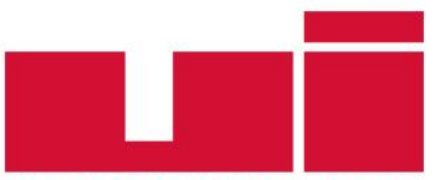

ULLUSLARARASIILIȘKiLER

Akademik Dergi

Yayın ilkeleri, izinler ve abonelik hakkında ayrıntılı bilgi:

E-mail: bilgi@uidergisi.com.tr

Web: www.uidergisi.com.tr

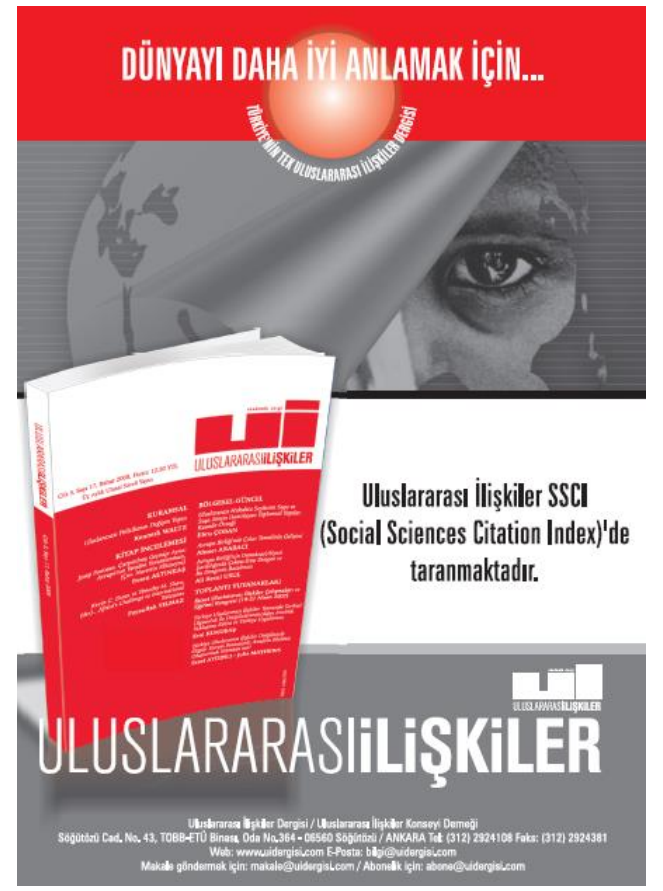

\title{
Enerji Jeopolitiğinin Uluslararası İklim Değişikliği Girişimleri Üzerindeki Etkisi
}

\section{Volkan Ş. EDİGER*}

* Prof. Dr., Enerji Sistemleri Mühendisliği Bölümü; Strateji Geliştirme ve Araştırma (STRAR) Koordinatörü; Enerji ve Sürdürülebilir Kalkınma Merkezi (CESD) Müdürü, Kadir Has Üniversitesi

Bu makaleye atıf için: Ediger, Volkan Ş., "Enerji Jeopolitiğinin Uluslararası İklim Değişikliği Girişimleri Üzerindeki Etkisi”, Uluslararası İlişkiler, Cilt 14, Say1 54, 2017, s. 45-70.

Bu makalenin tüm hakları Uluslararası İlişkiler Konseyi Derneği'ne aittir. Önceden yazılı izin alınmadan hiç bir iletişim, kopyalama ya da yayın sistemi kullanılarak yeniden yayımlanamaz, çoğaltılamaz, dağıtılamaz, satılamaz veya herhangi bir şekilde kamunun ücretli/ücretsiz kullanımına sunulamaz. Akademik ve haber amaçlı kısa alıntılar bu kuralın dışındadır.

Aksi belirtilmediği sürece Uluslararası Illişkiler'de yayınlanan yazılarda belirtilen fikirler yalnızca yazarına/yazarlarına aittir. UİK Derneğini, editörleri ve diğer yazarları bağlamaz. 


\title{
Enerji Jeopolitiğinin Uluslararası İklim Değişikliği Girişimleri Üzerindeki Etkisi
}

\author{
Volkan Ş. EDİGER \\ Prof. Dr., Enerji Sistemleri Mühendisliği Bölüm; Strateji Geliştirme ve Araştırma (STRAR) Koordinatörü; \\ Enerji ve Sürdürülebilir Kalkınma Merkezi (CESD) Müdürü, Kadir Has Üniversitesi, İstanbul. \\ E-posta: volkan.ediger@khas.edu.tr
}

\section{ÖZET}

Genel olarak iklim değişikliği girişimleri ile enerji jeopolitiği arasındaki ilişkinin analiz edildiği bu makalede, başta petrol fiyatlarındaki artı̧̧lar olmak üzere, enerji jeopolitiğindeki gelişmeler, 1965-2014 arasında enerji jeopolitiğinin şiddetlendiği ve durağanlaştı̆ı dönemlere ayrılarak, tarihsel bakış açısıyla incelenmiştir. Özel olarak, Kyoto Protokolü gibi iklim değişikliğinin önlenmesi konusunda yükümlülük getirmesi bakımından önemli bir anlaşma olarak kabul edilen uluslararası girişimlerin neden yeterince başarılı olmadığı araştırılmışıtır. Kyoto Protokolü özelinde başarısızlı̆ı̆ üç temel nedeni bulunmaktadır. Bunlardan birincisi ve en önemlisi dünya genelinde enerji jeopolitiğinin şiddetleniyor olmasıdır. İkinci neden ülkelerin farklı enerji ihtiyaçları ve farklı yerli enerji kaynaklarının bulunması, üçüncüsü de uygulamalarda devlet ve özel sektörün rolünün yeterince belirgin olmamasıdır. Yazar, iklim değişikliği konusundaki genel başarısızlığın başlıca nedenini enerji jeopolitiğindeki gelişmelere bağlamakta ve petrol krizleriyle somutlaşan küresel enerji politiğindeki mücadele dönemlerinin, iklim değişikliği gibi konulardaki uluslararası girişimlerin başarı şansını azalttığını savunmaktadır.

Anahtar Kelimeler: İklim Değişikliği, Uluslararası Girişimler, Enerji Jeopolitiği, Petrol Fiyatları.

\section{The Effect of Energy Geopolitics on International Climate Change Initiatives}

\begin{abstract}
In this article, in general, the relationship between international climate change initiatives and energy geopolitics was analyzed, and in particular the developments in energy geopolitics were investigated with a historical point of view by dividing the years between 1965 and 2014 into periods of geopolitical intensity and geopolitical stability based on long-term periodic variations in oil prices. More specifically, the reasons why international initiatives such as the Kyoto Protocol, regarded as an important agreement for imposing commitments in climate change mitigation, have not been sufficiently successful were investigated. Regarding the Kyoto Protocol, the failure stemmed from three main reasons. The first and the most important reason was the intensification of geopolitical tensions on a global scale. The second reason was the differences among states in terms of their energy needs and possession of indigenous energy sources. The last reason was the ambiguity regarding the role of the state and the market at the implementation level. The author links the general failure in the efforts to tackle climate change to the developments in energy geopolitics and argues that the competition periods in energy geopolitics, as observed during the oil crises, decrease the chances of success for international initiatives on climate change.
\end{abstract}

Keywords: Climate Change, International Initiatives, Energy Geopolitics, Oil Prices. 


\section{Giriş ${ }^{1}$}

Küresel iklim değişikliğinin çoğunlukla insan faaliyetlerinden kaynaklanması ve sonuçlarının canlı yaşamı üzerinde geri dönülmez olumsuz etkiler oluşturacak olması, onun çağımızın en önemli sorunları listesinin başında yer almasına neden olmaktadır. Bunun yanı sıra, sorunun aynı zamanda büyük çaplı ve küresel olması, konuyu uluslararası ilişkiler gündemininin üst sıralarına taşımaktadır.

Hükümetlerarası İklim Değişikliği Paneli’nce (Intergovernmental Panel on Climate Change, IPCC) "doğal nedenlerle veya insan faaliyetleriyle, iklimde zaman içinde gözlenen her türlü değişiklik", Birleşmiş Milletler İklim Değişikliği Çerçeve Sözleşmesi'nce (United Nations Framework Convention on Climate Change, UNFCCC), "iklimdeki doğal değişikliklere ilaveten, doğrudan ya da dolaylı olarak insan faaliyetlerinden kaynaklanan, küresel atmosferin kompozisyonunu bozan ve belirli bir zaman süresince iklimde gözlenen değişiklikler” şeklinde tanımlanan küresel iklim değişikliği (global climate change), 1980'lerin ortalarından itibaren bilimsel olarak tatmin edici düzeyde kanıtlanmış bir doğa olayıdır. $^{2}$

Konunun ayrıntılarıyla değerlendirilmesi amacıyla 1988'de kurulan ve günümüzde konuyla ilgili en önemli uluslararası organizasyon olarak bilinen IPCC'nin 5. Değerlendirme Raporu'na (AR5-5 ${ }^{\text {th }}$ Assessment Report) göre, karbondioksit, metan ve azot oksit gibi önemli sera gazlarının (SG, Greenhouse Gases-GHG) atmosferdeki yoğunluğu, birincil olarak fosil yakıtların, ikincil olarak da tarım arazilerinin kullanımı gibi insan faaliyetlerinden ötürü 1750'den beri sürekli yükselerek, sanayileşme öncesine göre sırasıyla $\% 40, \% 150$ ve $\% 20$ oranlarında artış göstermiştir. ${ }^{3}$ AR5 dünyadaki iklim sistemlerinde gözlenen değişimleri şöyle açılklamaktadır: Atmosferde; kara ve denizlerin birlikte yüzey sıcaklıkları $1880-2012$ yılları arasında ortalama olarak $0,85^{\circ} \mathrm{C}\left[0,65^{\circ} \mathrm{C}\right.$ ile $1,06^{\circ} \mathrm{C}$ arasında $]$ artmış ve $1850-1900$ ve $2003-2012$ dönemlerindeki toplam ortalama artış $0,78^{\circ} \mathrm{C}\left[0,72^{\circ} \mathrm{C}\right.$ to $\left.0,85^{\circ} \mathrm{C}\right]$ olmuştur. Okyanuslarda; su yüzeyinden 700 m derinliğe kadar olan üst kısımlarda 1971-2010 arasında kesin olarak, 1870-1971 arasında ise muhtemelen ısınma görülmektedir. Kriyosferde; Grönland ve Antartika'daki buz tabakaları ve buzullarda son 20 yıldır bariz bir kütle kaybı ve alan daralması gözlenmektedir. Deniz seviyeleri; 19. yüzyıl ortalarından beri ve 1901-2010 arasında, ortalama olarak $0.19 \mathrm{~m}$ [0.17 m ile $0.21 \mathrm{~m}$ arasında] yükselmiştir. Söz konusu bilimsel veriler, küresel iklim değişikliğinin ısınma, kuraklaşma, deniz seviyesi yükselimi ve iklim aşırılıkları oluşturarak, insanlığı derinden etkileyeceğini açıkça göstermektedir.

Bu önemli küresel sorunun ancak küresel çaplı faaliyetlerle çözülebileceği görüşü çerçevesinde, sorunun çözümünde ortak hareket etmek amacıyla 1970'lerde başlatılan uluslararası girişimler, 1992'de Rio de Janeiro'da düzenlenen Birleşmiş Milletler Çevre ve Kalkınma Konferansı'nda imzaya açlan ve 21 Mart 1994 tarihinde yürürlüğe giren UNFCCC bu alanda atılmış çok önemli adımlardır. Fakat konuyla ilgili uluslararası girişimlerin en önemlisi hiç kuşkusuz ki, ülkeleri gruplayarak bağlayıcı salım indirimi hedefleri tahsis eden Kyoto Protokolü'dür. Protokol, Ek-I olarak gruplandırdığı kalkınmış ülkeleri, 150 yıllık endüstriyel faaliyetlerinden ötürü atmosferdeki yüksek SG seviyelerinin asıl sorumlusu olarak kabul etmiş ve onlara "ortak fakat farklı sorumluluklar" prensibini uygulayarak, bu guruba dâhil olmayanlara nazaran daha ağır yükümlülükler getirmiştir. 2008'de başlayıp 2012'de

1 Yazar, çalışması esnasında literatür ve düzenleme çalışmaları yaparak değerli katkılarda bulunan Duygu Durmaz ile Gizem Özkut’a teşekkürlerini sunar.

2 "IPCC Fourth Assessment Report: Climate Change 2007", https://www.ipcc.ch/publications_and_data/ar4/wg2/ en/annexessglossary-a-d.html, (Erişim Tarihi 17 Şubat 2016).

3 Thomas F. Stocker et.al.,Climate Change 2013, The Physical Science Basis, Working Group I: Contribution to the Fifth Assessment Report of the Intergovernmental Panel on Climate Change, New York, Cambridge University Press, 2013, s.5-11. 
sona eren birinci yükümlülük döneminde, 37 endüstrileşmiş ülke ve Avrupa Topluluğu, SG'lerini 1990 seviyelerine göre ortalama olarak \%5 azaltımla (\%6 ile \%8 arasında) yükümlü kılınmıştır. 20132020 arasındaki ikinci yükümlülük döneminde ise, kapsamı ilkinden farklı olsa da, ülkelerin 1990 seviyelerine göre en az \%18'lik azaltım yükümlülüğü getirilmiştir.

Kyoto Protokolü’nün ilk yükümlülük döneminin 2012'de sonra ermesinden sonra, onun yerine geçecek bir anlaşma için üç yıl süreyle çok sayıda uluslararası görüşme yapılmıştır. Bunlardan en sonuncusu, UNFCCC uyarınca her yıl toplanan Taraflar Konferansı'nın (Conference of the PartiesCOP) 21.si, 30 Kasım-12 Aralık 2015 tarihleri arasında Fransa'nın başkenti Paris'te toplanmış ve yoğun görüşmeler sonucunda "Paris Anlaşması" (Paris Agreement) olarak anılan anlaşma üzerinde görüş birliğine varılmıştır. ${ }^{4}$ Fakat küresel iklim değişikliğiyle ilgili olarak insanlık tarihinin en kapsamlı ve yararlı anlaşması olarak Kyoto Protokolü halen yerini korumaktadır.

Bu nedenle, bu çalışmada, uzmanlarca birbirinden oldukça farklışekilde değerlendirilen Kyoto Protokolü ve hemen sonrasında gelen süreçte neden yeterince başarılı olunamadığı irdelenmektedir. Protokol, bazı uzmanlar tarafından "oldukça yaratıcı ve başarılı" olarak değerlendirilirken, bazıları Protokolü "yetersiz" bulmaktadır. ${ }^{5}$ Protolün başarılı olduğu değerlendirmesini yapanlar, genellikle, birçok ülkenin üstlendikleri yükümlülükleri, kısmen veya tamamen de olsa Protokol sayesinde salım azaltımını gerçekleştirebilmiş olmalarını önemli gelişmeler olarak görmektedirler. Bu kişiler, savlarına en güzel örnek olarak, yükümlülüklerini yerine getirerek salımlarını \%5 oranında düşüren Avrupa Birliği’ni $(\mathrm{AB})$ göstermektedirler. Diğer taraftan Kyoto Protokolü, öngörülen süreyi tam olarak tamamlayamaması, \%23 ile dünyada karbon dioksiti en büyük salıcı ülke olan ve bu nedenle \%7'lik bir azaltım yükümlülüğü altına alınan Amerika Birleşik Devletleri’nin (ABD) Protokolü onaylamayı reddetmiş olması ve gelişmekte olan ülkeler için bağlayıcı hedefler konulamaması nedenleri ile başarısız olarak da değerlendirilmektedir. ${ }^{6}$ Sabit kotaların getirilmesine itiraz eden $\mathrm{ABD}$, zorunluluk yerine gönüllülük sisteminin uygulanmasını önermiş, fakat 2007'deki Group of Seven+Rusya (G7) zirvesinde, AB liderleri tarafından bu öneriye şiddetle karşı çıkılmıştır. ${ }^{7}$ ABD'nin küresel SG salımının dörtte birinden sorumlu olması nedeniyle, bu tavrı Protokolün başarı şansını en başından düşürmüştür. Üstelik ABD'nin Kyoto Protokol'ünü reddi, Ek-II ülkelerinin uyum maliyetini de (compliance cost) etkilemiş; OECD ülkelerininki düşerken, geçiş ekonomilerininki artmıştır. ${ }^{8}$ Genel olarak değerlendirildiğinde, önemli sayılabilecek başarılarına rağmen Kyoto Protokolü’nün "beklenilen” ya da "olması gereken” düzeyde etkin ve geçerli olduğunu söylemek mümkün değildir. Daha sonra gerçekleştirilen, başta Paris Konferansı olmak üzere, çok sayıdaki uluslararası girişimin de yeterince başarılı oldukları söylenemez. Birçok uzman, konferans sonrası imzalanan anlaşmanın mevcut duruma önemli katkılar sağlamasına rağmen, nihai çözüm sağlamaktan uzak olduğu değerlendirmesinde hemfikirdir.

4 Bkz. “COP 21", https://unfccc.int/meetings/paris_nov_2015/session/9057.php ve “COP21, CMP11", http://www. cop21.gouv.fr/en/, (Erişim Tarihi 23 Şubat 2016).

5 Örneğin, Jon Hovi ve CICERO, “Towards a Better Compliance System for the Climate Regime?”, Chistopher P. Vasser (der), The Koyoto Protocol: Economic Assessments, Implemetation Mechanisms and Policy Implications, New York, Nova Science Publishers, Inc., 2009, s.107-117.

6 Örneğin, Peter Cassidy ve Mark Raymont, "Has the Kyoto Protocol Got a Future without the USA?”, Refocus, Cilt 2, No.5, Haziran 2001, s.28-29; Joshua W. Busby, "Climate Change Blues: Why the United States and Europe Just Can't Get Along”, Current History, Mart 2003, s.114; Vasser, The Kyoto Protocol, s.vii-xiii.

7 Saul Bernard Cohen, Geopolitics: The Geography of International Relations, Rowman \& Littlefield, 2015, s.214.

8 Alan Mannea ve Richard Richels, "US Rejection of the Kyoto Protocol: The Impact on Compliance Costs and $\mathrm{CO}_{2}$ Emissions”, Energy Policy, Cilt 32, 2004, s.453. 
Paris Konferansı́nın günümüze değin en fazla ilgi gören iklim değişikliği zirvesi olduğu söylenebilir. Aralarında 130'dan fazla devlet başkanının bulunduğu 195 temsilci ile yüzlerce uzman konferansa katılmış ve iklim değişikliği konusunda Kyoto sonrasında devreye girecek olan bağlayıcı bir anlaşmanın imzalanmasına gayret etmişlerdir. ${ }^{9}$ Fakat konferans sonunda imzalanan 29 maddelik Paris Anlaşması da en az Kyoto Protokolü kadar eleştiriye maruz kalmıştır. ${ }^{10}$ Anlaşma’nın en fazla eleştirilen tarafları anlaşmanın SG azaltma hedefleri ve bunun finasmanı olmuştur. Görüşmelerde ülkelerin hemen hepsi iyi niyet beyanında bulunarak, kendi açılarından farklı hadefleri savunmuşlardır. Örneğin, AB 1990 seviyesine göre, 2030 itibarıla \%40’lık bir azaltma yapmayı, ABD 2005 seviyesine göre, 2015 itibarıyla \%28' lik bir azaltma yapmayı, Çin 2030'da SG salımında zirvesiye ulaştıktan sonra net olarak bir azaltmaya gitmeyi, Türkiye ise 2030 itibarıyla SG salımını \%21 azaltmayı hedeflemiştir. Fakat bu hedefler 2020'de yürürlüğe girmesi beklenen anlaşmada yer almamış, 4. Maddede, gelişmiş ülkelerin mutlak salım azaltım hedefleri belirleyerek konuyla ilgili öncülüklerine devam edecekleri; gelişmekte olan ülkelerin ise, azaltım konusundaki gayretlerini artırmayı sürdürecekleri ve bütün ülkelerin kendi koşulları çerçevesinde bu konudaki gayretlerini ekonomilerinin bütününe yayacakları belirtilmiştir. Tarafların, konuyu ayrıntılı çalışarak ulaşmak istedikleri hedefleri belirlemeleri ve bu hedeflerini diğer ülkelere bildirmeleri istenmektedir.

İklim değişikliğiyle ilgili mücadelenin finansmanı da eleştirilen konuların başlarında yer almaktadır. Anlaşmanın 9. Maddesinin 3. Paragrafında, gelişmiş ülkelerin, gelişmekte olan ülkelere ihtiyaçlar ve öncelikler göz önüne alınarak-2025'e kadar 100 milyar ABD doları yardım yapmaya niyetli ve gayretli oldukları belirtilmektedir. Fakat maddi ve teknik desteklerin 2025 sonrasını da kapsaması gerektiği ve yardım konusunu ülkelerin inisiyatifine bırakmak yerine, dağıtım ve denetlemenin Dünya Bankası gibi bir kuruluşun çatısı altında yapılmasının daha doğru olacağı savunulmaktadır. Bu konuda, gelişmiş ülkelere karşı geçmişteki örneklerden kaynaklanan ciddi bir bir güvensizlik söz konusudur.

Paris Konferansı’nın başarılı sayılabilecek en önemli sonucu, küresel ortalama sıcaklık artış limitinin önceden $2^{\circ} \mathrm{C}$ 'de tutulması üzerinde fikir birliğine varılmış olmasına rağmen, zirvede yapılan görüşmelerde -son çalışmaların bunun yetmeyeceği yolunda olması nedeniyle- limitin $1,5^{\circ} \mathrm{C}$ olarak belirlenmesi olmuştur. Anlaşmanın 2. Maddesinde, iklim değişikliğinin risklerinin ve etkilerinin azaltılabilmesi için, mevcut şartlarda kürsel ısınmanın $2{ }^{\circ} \mathrm{C}$ 'nin altında tutulmasının yeterli olmayacağ 1 gerekçesiyle, limitin $1.5{ }^{\circ} \mathrm{C}$ ye yükseltildiği belirtilmiştir. Bunun başlıca nedeni olarak 2030'da atmosferdeki salım miktarının 55 gigatona çıkacağı öngörüsü gösterilmektedir. Konferansın bir diğer başarılı sonucu ise, coğrafi değişikliklerden en fazla etkilenecek olan, 700 milyonu temsil eden ve alt ve orta gelir düzeyinde yaşayan insanlardan oluşan ülkelerin oluşturduğu Vulnerable-20 (V20) Grubu'nun ortaya çıkması olmuştur.

$\mathrm{Bu}$ çalışmanın esas amacı, dünya genelinde diğer uluslararası sorunlara kıyasla farkındalığın daha yüksek seviyelerde bulunmasına ve SG azaltımı ve sabitleştirilmesi (mitigation) ile zararlarına uyum (adaptation $)^{11}$ konularında küresel çapta oldukça yaygın bir konsensüs bulunmasına rağmen, küresel iklim değişikliğine yönelik uygulamalar konusunda neden yeterli başarının sağlanamıyor olmasını incelemektir. Yazar bunun başlıca nedenini enerji jeopolitiğindeki gelişmelere bağlamakta ve petrol krizleriyle somutlaşan, küresel enerji politiğindeki mücadele dönemlerinin, iklim değişikliği

9 "COP 21".

10 "COP21, CMP11".

11 "Mitigation and Adaptation”, http://climate.nasa.gov/solutions/adaptation-mitigation/, (Erişim Tarihi 23 Ocak 2016). 
gibi konulardaki uluslararası girişimlerin başarı şansını azalttığını savunmaktadır. Bu tezin alt yapısını oluşturmak için önce, petrol fiyatlarındaki artışlar başta olmak üzere enerji jeopolitiğindeki gelişmeler tarihsel bakış açısıyla incelenmiş, ilerleyen bölümlerde de ülkelerin farklı ihtiyaçları ve yerli kaynakları ile uygulamalarda devlet ve özel sektörün rolü değerlendirilmiştir. Son bölümde ise, çalışmadan elde edilen önemli sonuçlar ile sonraki çalışmalar için öneriler verilmiştir. Çalışmada kullanılan istatistiki veriler, aksi belirtilmedikçe British Petroleum (BP) Statistical Review of World Energy 2015'ten temin edilmiştir. ${ }^{12}$

\section{Enerji Jeopolitikası}

İçinde bulunduğumuz zaman dilimi, enerji kaynakları arasındaki yer değiştirme (substitution/ shift) açısından, fosil yakıt çağından düşük karbonlu yeşil enerji çağına geçişi temsil etmekte olup, bu dönemde doğal gaz bir geçiş yakıtı (transition fuel) ya da geçici bir çözüm (interim solution) olarak kullanılmaktadır. ${ }^{13}$ Tarihsel olarak gözlediğimiz enerjide geçiş dönemi özelliklerinin önemli bir kısmının yaşandığı bu dönemde, büyük güçler arasında, özellikle enerji kaynakları ve onların tüketicilere nakil güzergâhları üzerindeki mücadelenin (enerji jeopolitiği) şiddetlenmesiyle petrol fiyatları yükselerek, ekonomik ve siyasi krizlere neden olmaktadır. ${ }^{14} \mathrm{Bu}$ tür zamanlarda, daha çok yumuşak gücü (soft power) gerektiren küresel iklim değişikliği gibi konularda yeterince başarılı olunamamakta, küresel oyuncular sert güce (hard power) daha fazla ağırlık vermektedir.

\section{3-1986 Dönemi}

Petrol fiyatlarıyla enerjijeopolitiğiarasındakiyakın ilginin vurgulandığı Şekil 1'de, 1973-1986 arasındaki I. ve II. Petrol Krizi ile 1998-günümüz arasındaki III. ve IV. Petrol Krizi dönemleri ile aradaki 19861998 arası durağan dönem gösterilmektedir. ABD’de, 1859'da ilk modern rotari petrol kuyusunun açılmasının ardından petrol ticaretinin başladığı 1861'den günümüze kadarki sürede varil başına ABD doları cinsinden ham petrol fiyatları incelendiğinde, 1970'lere kadarki cari fiyatların genellikle en fazla 2 \$ civarında seyrettiği görülmektedir. Bu dönemde, özellikle gelişmiş ülke ekonomileri, bol ve ucuz yakıttan istifade etmiş ve sanayileşmelerini farklı tarihlerde tamamlayarak kalkınmış ülkeler sınıfına dâhil olmuşlardır. Fakat daha sonra, hafif kıpırdamalarla, 1971'de 2,24\$, 1972'de 2,48\$, 1973 'te 3,29\$ olan fiyatlar, ilk kez 1974’te anormal bir artışla 11,58\$’a kadar yükselmiştir. Bu olay, I. Petrol Krizi olarak adlandırılmaktadır. Görünürde, Suriye ve Mısır’ı İsrail’e Yom Kippur saldırısını düzenlemesiyle Ortadoğu'da başlayan uluslararası kriz nedeniyle yükselmeye başlayan fiyatlar, kısa bir durgunluk dönemininin ardından tekrar hareketlenerek 1977'de 13,92 \$dan 1980'de 36,83\$'a kadar çıkmıştır; bu da II. Petrol Krizi olarak adlandırılmaktadır.

12 "Statistical Review of World Energy 2015", http://www.bp.com/statisticalreview, (Erişim Tarihi 11 Ocak 2016).

13 Volkan Ş. Ediger, "Energy Transition Periods: Lessons Learnt from the Past”, Abu Dabi, The Emirates Center for Strategic Studies and Research (ECSSR) Publications, 2011, s.175-202.

14 Volkan Ş. Ediger, Enerjide Yeni Dünya Düzeni ve Türkiye, Akademi Forumu No.67, Ankara, Türkiye Bilimler Akademisi (TÜBA) Yayınları, 2011, s.1-62; Robert D. Kaplan, “The Geopolitics of Energy”, 2 Nisan 2014, http://www.ctcitraining. org/topdocs/GeopoliticsEnergy.pdf, (Erişim Tarihi 03 Mart 2016), s.1-3. 
Şekil 1 Enerji Jeopolitiğinin Şiddetlendiği Dönemler ve Petrol Fiyatları, 1960-2014.

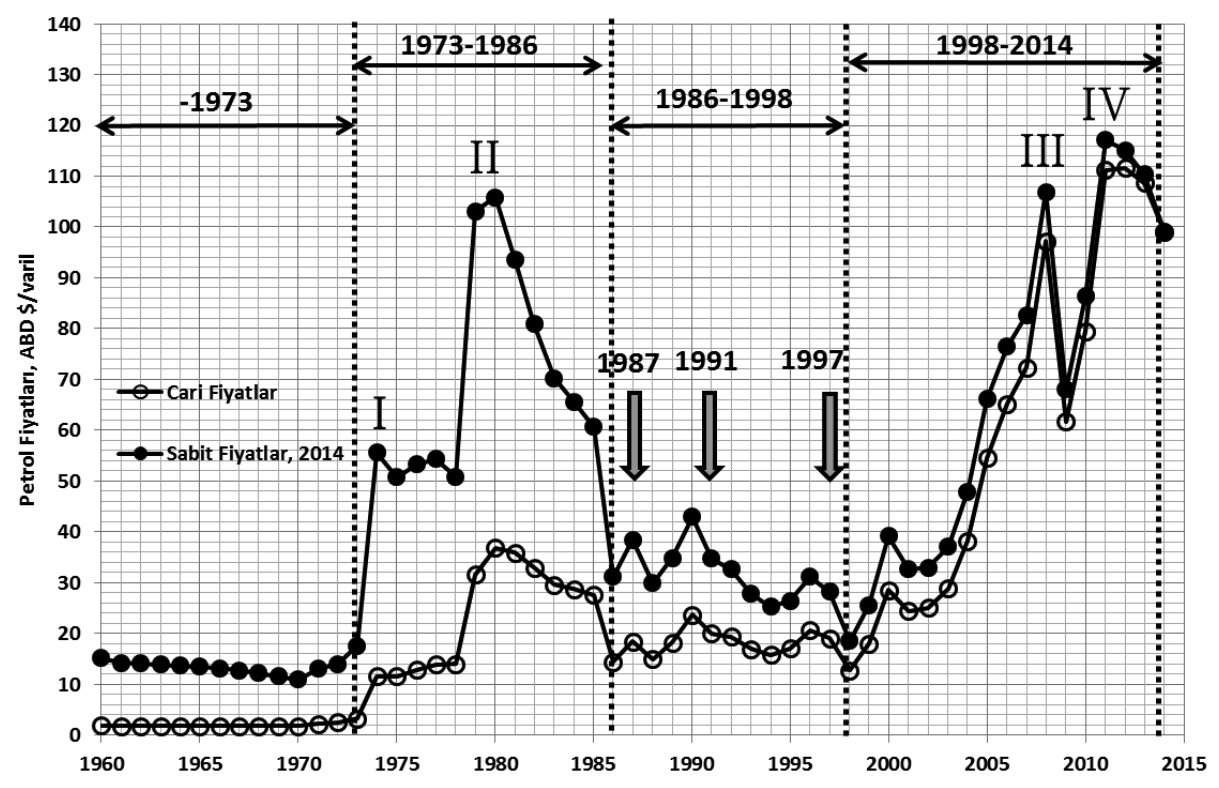

Petrol fiyatlarının 1973-1980 arasındaki sadece 7 yılda 11 kat artması, petrol ithal eden ülkeler başta olmak üzere bütün ekonomileri derinden etkilemiş, küresel çapta ciddi krizlere neden olmuştur. Ekonomik krizin uluslararası siyasete yansıması da gecikmemiş, İran'da, ABD’nin her türlü desteğine sahip Şah Ruza Pehlevi, Ocak 1979'da ülkeyi terk ederek, yerini Ayetullah Humeyni’ye bırakmak zorunda kalmıştır. Daha sonra, Kasım 1979'da Tahran'daki Amerikan Büyükelçiliği radikal İslamcı militanlar tarafından ele geçirilmiş, birkaç hafta sonra da Sovyetler Birliği Afganistan’a girmiştir. Eylül 1980'de ise, Irak'ın İran'ı işgaliyle 1988’e kadar sürecek olan İran-Irak Savaşı başlatılmıştır.

Büyük petrol üreticisi ülkelerin petrol üretimlerinin tarihsel gelişimi incelendiğinde -her ne kadar ekonomik ve siyasi kriz olarak görünse de-1973-1980 arasındaki küresel krizlerin temelinde enerji jeopolitiği yattığı anlaşılmaktadır (Şekil 2). ABD'deki petrol sorunu aslında 1950'li yılların ikinci yarısında ortaya çıkmaya başlamıştır. M. C. King Hubbert, 1956'da kümülatif üretimin zaman serisi eğrisi, 1959'da lojistik eğri olarak hesapladığı simetrik çan eğrisini kullanarak ABD’nin petrol üretim gelişimini incelemiş ve üretimin 1970'te zirveye çıkacağı ve belirli bir zirve ya da plato döneminden sonra düşüşe geçerek, yatay zaman eğrisini teorik olarak bir noktada keseceği öngörüsünde bulunmuştu. ${ }^{15}$ Nitekim 1970'de 11,297 milyar varillik günlük üretimle dünya listesinde ilk sırada olan ABD, 1976'dan sonra Sovyet Sosyalist Cumhuriyetler Birliğinnin (SSCB) gerisinde kalıp ikinci siraya yerleşerek, günlük üretimi 9,736 milyar varile gerilemiştir. Aynı yıl, üçüncü sırada ise, 8,762 milyar varillik günlük üretimi ile Suudi Arabistan bulunmaktadır.

15 M.C. King Hubbert, "Nuclear Energy and the Fossil Fuels", Drilling and Production Practice, American Petroleum Institute, No.95, 1956; M.C. King Hubbert, "Techniques of Prediction with Application to the Petroleum Industry", Proceedings of the $44^{\text {th }}$ Annual Meeting of the American Association of Petroleum Geologists, Dallas, Shell Development Company, 1959. 
Şekil 2 Büyük Ülkelerin Petrol Üretimleri, 1965-2014.

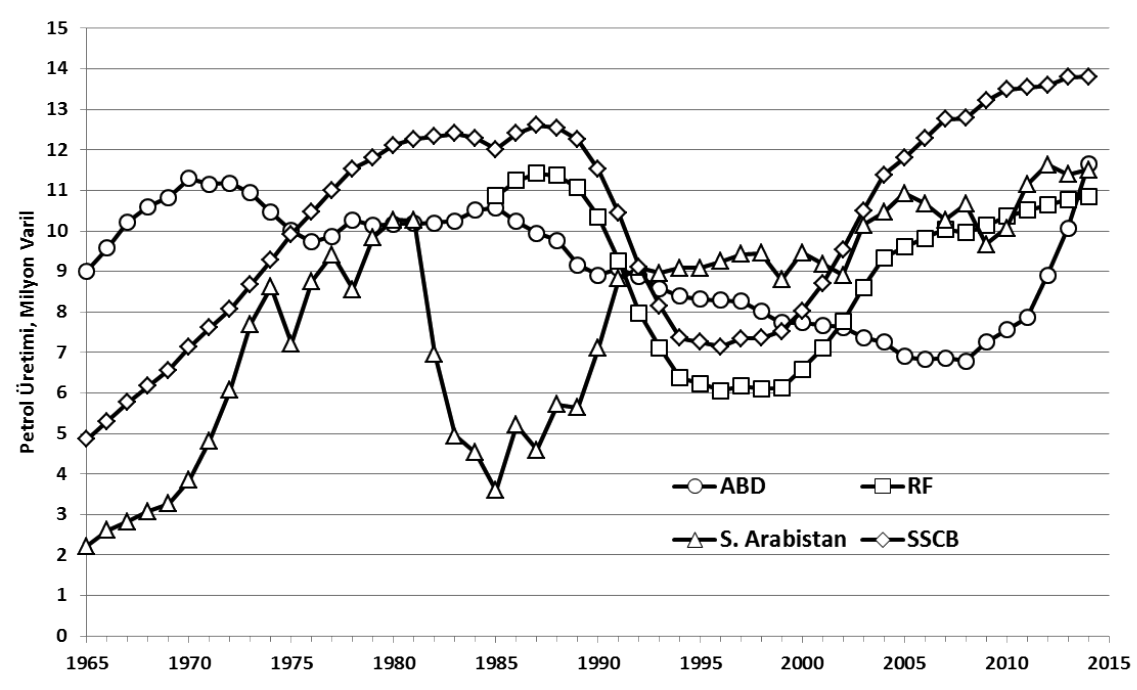

Petrol endüstrisinin varlık göstermeye başladığı 1859 'dan beri dünyanın en büyük petrol üreticisi konumunu koruyan dönemin hegemonik gücü $\mathrm{ABD}$ açısından bu, kabul edilebilir bir durum değildi. Nitekim petrol krizleri ile artan fiyatlar ve ülkede oluşturulan yeni enerji güvenliği tedbirleri sayesinde üretimini 1976-1985 arasında az çok sabit tutarak ve hatta biraz da artırarak, 10,580 milyar varile çıkarabildi. ABD sadece üretimde değil, tüketimde de büyük başarı sağlayarak 1973-1975 arasında 1 milyar varile yakın, 1978-1983 arasında ise 3,5 milyar varilden fazla tasarruf sağladı ve 1973'te 17,318 milyar varil olan tüketimini 1983'te 15,235 milyar varile kadar düşürdü. Böylece, 10 yll içinde, 19761978 arasındaki geçici yükselişe rağmen, ABD’nin petrol tüketimi net 2 milyar varil azalmış oldu.

Üretim ve tüketimde sağlanan bu başarılar, 1977'de \%54'e kadar düşmüş bulunan, ülke petrol ihtiyacının yerli kaynaklardan sağlanma oranını, 1982-1984 arasında \%67’ye kadar çıardı. Sadece petrolde değil, doğal gazda da benzer durumlar yaşanmıştı. Dünyanın en büyük petrol üreticisi ve tüketicisi olan ABD'deki bu gelişmeler, doğal olarak bütün dünyaya yansımış ve dünya günlük petrol üretim/tüketimi 1974-1975 arasında 2,791 milyar varil, 1979-1983 arasında ise 9,445 milyar varil kadar düşmüş ve 1975-1979 arasındaki kısmi artışa rağmen, 1974-1983 arasında net olarak yaklaşık 2 milyar varil tasarruf sağlanmıştı. Bir başka deyişle, petrol krizleri olmasaydı ve 1965-1973 trendi sonraki 10 yılda da benzer şekilde devam etseydi, 1973'teki petrol tüketiminin 5831,1 Mtep olması beklenirdi. Hâlbuki 1983 dünya petrol tüketimi 2754,3 Mtep olarak gerçekleşmiştir, yani beklentinin \%53'lük bir oran kadar altında kalmıştır.

Petrol krizinin önemli sonuçlardan bir diğeri de, özellikle ithal petrole bağımlı ülkelerin petrol arzına olan güvensizliklerinin artmasıyla, alternatif enerji kaynaklarına yönelmeleri olmuş ve yerli kömür en makul alternatif olarak belirmiştir. 1960'ların ilk yarısında, 1400 Mtep civarında bir miktarla petrol tüketimiyle eşitlenmiş kömür tüketimi, petrol krizlerinden sonra, artışını sürdürerek 1989'da 2266,6 Mtep miktarına ulaşmıştır. 1973-1983 arasındaki 10 yllda, petrol tüketimi neredeyse hiç artmayarak (hatta 2763,2 Mtep’ten 2754,3 Mtep’e düşerek) yaklaşı aynı noktaya gelirken, kömür tüketimi 1530,6 Mtepten 382,7 Mtep'lik bir artışla 1913,3 Mtep’e kadar yükselmiştir. Bu süre zarfında, kömür tüketimi petrol fiyatlarıla ters orantılı bir seyir izlemiş, petrol fiyatlarının artış dönemlerinde kömür tüketimi artmış, durağan dönemlerde ise sabit kalmıştır. Örneğin, daha sonraki 1986-1998 durağan döneminde, 
kömür tüketimi 2248,2 Mtep-2281,8 Mtep arasında kalırken, petrol fiyatlarının yeniden artmaya başlaması üzerine çok daha hızla yükselmeye başlamıştır. Bu süre zarfında doğal gaz tüketimi ise, petrol fiyatlarından bağımsız olarak istikrarlı artışını sürdürmüştür. Kısaca, petrol kömür ile ikame edilmiştir.

Büyük ülke ve grupların 1965-2014 arasındaki kömür tüketimleri incelendiğinde, jeopolitik dönemlerin etkisi bariz bir şekilde görülmektedir (Tablo 1). İki süper gücün kömür politikaları 1978'e kadar birbirleriyle oldukça dengeli ilerlemiştir; 1965'te ABD 291,8 Mtep, SSCB 297,4 Mtep, 1978'de ise ABD 346,8 Mtep, SSCB 345,6 Mtep olarak gerçekleşmiştir. Fakat daha sonraki yıllarda ABD’nin tüketimi artarak, SSCB'ninki yatay seyrederek ya da azalarak devam etmiş ve Sovyetler Birliği'nin dağıldığı 1991'de aralarındaki fark, ABD'nin lehine 193 Mtep'e kadar çıkmıştır. Bu dönemde Hindistan'ın tüketimi sürekli artış gösterirken, $\mathrm{AB}$ ise kömür tüketimini mümkün olduğu kadar artırmamaya çalışmıştır. 1965 'te 508,2 Mtep iken, oldukça yatay bir seyir izleyerek 1989'da 492,8 Mtep olarak gerçekleşen AB kömür tüketimi, o tarihten sonra sürekli olarak azalarak günümüzdeki seviyesi olan 269,8 Mtep’e kadar düşmüştür. AB’nin kömürden mümkün olduğu kadar kaçınma politikasına rağmen, tüketim, kriz döneminde az da olsa artışa uğramış, 1973’te 446,2 Mtep'den 1987'de 502,7 Mtep'e çıkmıştır. Kısaca, 1973-1986 arasındaki jeopolitik gerilimin arttığı dönemde SSCB dışındaki hemen her ülke, değişik oranlarda da olsa, petroldeki dışa bağımlılığın önüne geçmek için yerli kömüre ağırlık vermişlerdir.

Tablo 1 Büyük Ülke ve Grupların Kömür Tüketimleri, 1965-2014

\begin{tabular}{|l|r|r|r|r|r|r|r|r|r|r|r|}
\hline Mtep & 1965 & 1970 & 1975 & 1980 & 1985 & 1990 & 1995 & 2000 & 2005 & 2010 & 2014 \\
\hline Non-OECD & 515,9 & 597,7 & 720,4 & 826,0 & 986,9 & 1124,7 & 1194,4 & 1233,0 & 1934,7 & 2481,2 & 2829,3 \\
\hline OECD & 878,9 & 881,8 & 841,7 & 984,0 & 1090,0 & 1108,6 & 1063,3 & 1136,4 & 1187,7 & 1130,0 & 1052,5 \\
\hline ABD & 291,8 & 309,1 & 319,1 & 388,6 & 440,4 & 483,1 & 506,2 & 569,0 & 574,5 & 525,0 & 453,4 \\
\hline Hindistan & 35,5 & 37,6 & 48,1 & 56,7 & 72,5 & 95,5 & 125,0 & 144,2 & 184,4 & 260,2 & 360,2 \\
\hline Avrupa Birliği & 508,2 & 477,2 & 429,8 & 484,7 & 503,3 & 457,5 & 364,3 & 320,5 & 316,6 & 281,3 & 269,8 \\
\hline SSCB & 297,4 & 312,2 & 342,0 & 337,5 & 333,0 & 317,2 & 197,0 & 173,8 & 165,5 & 167,6 & 162,6 \\
\hline Dünya & 1394,8 & 1479,5 & 1562,1 & 1810,0 & 2076,9 & 2233,3 & 2257,7 & 2369,4 & 3122,4 & 3611,2 & 3881,8 \\
\hline
\end{tabular}

Petrolün yerli kömürle ikamesi daha çok Ekonomik Kalkınma ve İşbirliği Örgütü (Organisation for Economic Co-operation and Development-OECD) üyesi olmayan, az gelişmiş ya da gelişmekte olan ülkelerde görülmektedir. OECD ve OECD üyesi olmayanların (Non-OECD) kömür tüketimleri incelendiğinde, 1965'te OECD (878,9 Mtep) ile non-OECD (515,9 Mtep) arasında OECD lehine 363 Mtep'lik fark varken, her ikisinin de artmasına rağmen, birinin artış hızının diğerinden daha fazla olması nedeniyle tüketimlerin 1989'da 1132-1134 Mtep arasında eşitlendikleri görülmektedir. Daha sonra non-OECD'nin kömür tüketimi 1990'larda çok yavaş, 2000'lerde çok hızlı artarak, OECD ile arasındaki farkı ciddi ölçüde artırmıştır. Burada önemli olan, OECD’nin kömür tüketimi azalma eğilimindeyken petrol kriziyle birlikte yön değiştirmiş olmasıdır. 1972'de 835,8 Mtep’e kadar düşen OECD kömür tüketimi, petrol kriziyle birlikte artmaya başlamış ve 1989'da 1134,3 Mtep ile zirveye taşınmıştır. Tüketim, bundan sonraki durağan dönemde oldukça yatay seyredecek ve III. petrol krizleri ile birlikte tekrar yükselmeye başlayacaktır.

Ülkelerin petrol üretimini artırarak ve kömüre daha fazla ağırlık vererek, enerji karışımları içindeki yerli kaynak oranını artırmaya yönelik stratejiler geliştirmesinin yanı sıra, ABD’nin hayata geçirdiği diğer bir strateji de, petrol kaynakları konusunda uluslararası düzeyde uzun vadeli güvenlik önlemlerine yönelmek olmuştur. Bu konudaki ilk adım, 1969'da dönemin ABD Başkanı Richard M. Nixon tarafından açıklanan ve özellikle Ortadoğu'daki petrollerin korunması işinin ABD yerine 
müttefik ülkeler tarafından yapılmasını öngören doktrinden vazgeçilmesi olmuştur. ${ }^{16}$ Ocak 1980 'de açıklanan Carter Doktrini ile artık "Basra Körfezi’ndeki ulusal çıkarların korunması için gerekirse askerî güç kullanımı” uygulamasına geçilmiştir. ABD’nin petrol ithalatı açısından bağımlı olduğu bölgelerin korunmasının "Amerika'nın baş sorumluluğu” olduğunu açıklayan Carter’a göre, "Körfez petrolüne erişim ülke güvenliği için hayati öneme sahipti” ve Amerika, "askerî güç de dâhil olmak üzere gereken her şeyi yapmaya hazır” olmalıydı.” Yeni doktrinle birlikte, Orta Doğu’yu korumak amacıyla ilk defa kendi topraklarında (Tampa, Florida'daki MacDill Hava Üssü) Rapid Deployment Joint Task Force (RDJTF) adlı bir kuvvet oluşturulmuştur. Bu birlik daha sonra, Ocak 1983'te güçlendirilerek ABD Merkez Kuvvetler Komutanlı̆̆ (United States Central Command-CENTCOM) şekline getirilmiş ve bu birime Körfez'de her türlü operasyon yapma yetkisi verilmiştir. Küresel petrol akışından sorumlu bu yeni merkez Mısır'dan Kırgızistan’a kadar 3000 millik bir bölgeye uzanan 25 Müslüman ülkeyi kapsamaktaydı ve dünyanın diğer bölgeleri için de Miami'de Southern Command (SOUTHCOM), Stuttgart'da European Command (EUROCOM), Honolulu'da Pacific Command (PACOM), Springs, Colorado'da da Northern Comand (NORTHCOM) kurulmuştu.

Görüldüğü gibi, 1973 ve 1979 Petrol Krizleri’nin ardından ithal petrole bağımlılık ülke ekonomileri için oldukça önemli hale gelmiş ve enerji güvenliği konusu bilim adamları ve siyasiler tarafından geniş biçimde tartışılmıştır. Bu dönemde enerji güvenliği ülke güvenliği ile eş değerde tutularak, güvenliğin ülkelerle sınırlandırılamayacağı, bunun küresel bir sorun olduğu görüşü yaygınlaşmıştır. ${ }^{17}$ İhtiyaçlarını karşılayabilecek düzeydeki petrol kaynaklarından yoksun birçok gelişmiş ülkenin, jeopolitik açıdan istikrarsız ülkelere bağımlı olmaları ulusal güvenlik kapsamı içinde değerlendirilmeye başlamıştır. ${ }^{18}$

Böylesine bir dönemde, ülkelerin güvenliğini ekonomik ve siyasi açıdan doğrudan ilgilendirmeyen iklim değişikliği sorunu, doğal olarak enerji arz güvenliğinin gölgesinde kalmak zorunda kalmıştır. Konuyla ilgili olarak bu dönemde hayata geçirilen faaliyetler de genellikle, petrol gibi fosil yakıt rezervlerinin yenilenemeyen ve tükenebilen kaynaklar olduğu vurgusu ile kaynak sıkıntısı (resource scarcity) ve çevre duyarlılı̆̆ının (environmental awareness) artırılması konularına odaklanılmıştır. 1973 krizi başlamadan hemen önce, Ocak 1972'de önce The Ecologist dergisinde ${ }^{19}$ konuyla ilgili makaleler yayınlanmıs, daha sonra gelen yoğun talep üzerine Eylül 1972'de, Blueprint for Survival başlıklı kitap basılmıştır. ${ }^{20} \mathrm{Bu}$ çalışmanın en büyük özelliği "sürdürülebilirlik" (sustainability) tanımının ilk kez burada kullanılmış olmasıdır. 5-16 Haziran 1972 tarihlerinde, çevresel bozulmaya karşı acil önlemler alınması konusunda fikir birliğine varılmış olması dışında somut bir sonucu olmasa da Birleşmiş Milletler tarafından düzenlenen dünyanın ilk insan çevresi (human environment) zirvesi, Stockholm'de yapılmıştır. Aynı yıl, Massachusetts Institute of Technology araştırmacılarının Roma Klübü (Rome Club) adlı Sivil Toplum Kuruluşu için hazırladıkları The Limits to Growth kitabı da ilgili camiada önemli etkiler bırakmıştır. ${ }^{21}$ Kritik enerji sorunlarına değinilen bu kitapta, aşırı enerji tüketiminin sınırlı olan kaynak rezervlerinin kısa sürede tükenmesine neden olacağı ve bir yanda

16 Volkan Ş. Ediger, “Enerji Arz Güvenliği ve Ulusal Güvenlik Arasındaki İlişki”, Enerji Arz Güvenliği, Ankara, SAREM Yayınları, 2007, s.13-15.

17 Simon Dalby, “Environmental Insecurities: Geopolitics, Resources and Conflict”, Economic and Political Weekly, Cilt 38, No.48, 2003, s.5073.

18 Ausilio Bauen, "Future energy sources and systems-Acting on climate change and energy security", Journal of Power Sources, Cilt 157, 2006, s.893.

19 The Ecologist, Cilt 2, No.1, 1972.

20 “The Archive, 1970-2000., http://www.theecologist.info/page33.html, (Erişim Tarihi 09 Ocak 2016).

21 Donella H. Meadows et.al., Limits to Growth, Universe Book, 1972, s.205. 
arzda azalma görülürken diğer yanda hava kirliliğinde artış olacağı çarpıcı bir dille anlatılmaktadır. ${ }^{22}$ Görüldügü gibi, bu dönemde üzerinde en fazla durulan konu "tek bir ortak gezegenimiz olduğu" ve "geleceğimiz için onu nasıl kullandığımızın önemli olduğu” dur. ${ }^{23}$

\section{6-1998 Dönemi}

Enerji jeopolitiğinin şiddetlendiği 1973-1986 döneminin ardından, petrol fiyatlarının 12,72-23,73\$/ varil bandı arasında değiştiği (ortalama 17,80\$/varil), 1986-1998 arasındaki 13 yıllık durağan döneme geçilmiştir (Şekil 1). Dünyada ekonomik ve siyasi açıdan görece istikrarlı geçen bu dönem, iklim değişikliğinin gelişimine son derece müsait bir ortam hazırlayarak, insanlık tarihinin bu alandaki en önemli üç uluslararası faaliyetinin gerçekleşmesini sağlamıştır. Petrol fiyatlarının durağanlığının ortaya çıkardığı barış ve istikrarın dünya genelinde hâkim olduğu bu dönemde, ayrıca, ekonomide devletçilikten uzaklaşıp özelleştirmeye ağırlık verilerek piyasalar güçlendirilebilmiştir.

İklim değişikliğiyle ilgili olarak, 1987'de, Birleşmiş Milletler tarafından Dünya Çevre ve Gelişme Komisyonu (The World Commission on Environment and Development) adıyla, dönemin Norveç Başbakanı Gro Harlem Bruntland başkanlığında kurulan komite kısa sürede çalışmalarını tamamlayarak Brundtland Report olarak bilinen raporu yayınlamışır. ${ }^{24}$ "Sürdürülebilir kalkınma" (sustainable development) ilk defa bu raporda tanımlanmış ve yenilenebilir enerji kaynakları bu tarihten sonra daha çok devreye girmeye başlamıştır. İklim değişikliğiyle mücadelenin kapsamını genişleterek önemli bir kavram haline gelen sürdürülebilir kalkınma, raporun 27'inci maddesinde, "günümüzün ihtiyaçlarının, gelecek nesillerin kendi ihtiyaçlarını karşılama imkân ve kaabiliyetlerine zarar vermeden karşılanması” olarak özetlenmektedir. ${ }^{25}$

Bruntland Raporu'nun ardından iklim değişikliğiyle ilgili olarak her beş senede önemli birer adım atılmış; 1992'de Brezilya'nın Rio de Janerio kentinde ve 1997'de Japonya'nın Kyoto kentinde iklim değişikliği zirveleri toplanmıştır. Bunlardan ilkinin sonucu olarak, 1994’te UNFCCC ve ikincisinin sonucu olarak da 2005'te Kyoto Protokolü devreye girmiştir. 11 Aralık 1997'de imzalanmasına rağmen, ancak 16 Şubat 2005'te yürürlüğe girebilen Kyoto Protokolü, hiç kuşkusuz iklim değişikliği konusunda uluslararası düzeyde onaylanmış en önemli anlaşmadır. Protokol, UNFCCC'nin resmi internet sayfasında, "Taraflara uluslararası düzeyde bağlayıcı salım azaltımı hedefleri koyan ve UNFCCC ile bağlantılı olarak yapılan uluslararası bir anlaşma” olarak tanımlanmaktadır. ${ }^{26}$

Bu dönemde iklim değişikliği ile enerji güvenliği arasında sağlam bağlar tesis edilmiş ve ortaya "çevre güvenliği”" (environmental security) kavramı çıkmıştır. Özellikle ABD ve AB gibi Batılı ülkelerde çevre güvenliği konusundaki tartışmalarda, en az kaynak kıtlığı kadar çevre bozulmalarının da güvenlik tehditleri ortaya çıkarabileceği ve gerilimi artırarak çatışma ve savaş tehlikesini doğrurabileceği

22 N.H. Afgan et.al., "Sustainable Energy Development", Renewable and Sustainable Energy Reviews, Cilt 2, 1998, s.235-286; J.R. Siche et.al., "Sustainability of Nations by Indices: Comparative Study Between Environmental Sustainability Index, Ecological Footprint and the Energy Performance Indices”, Ecological Economics, Cilt 66, 2008, s.628-637.

23 Dalby, "Environmental Insecurities” s.5073.

24 Gro Harlem Bruntland (der.), Our Common Future, The World Commission on Environment and Development, Oxford, Oxford University Press, 1987.

25 "Item 27: Humanity has the ability to make development sustainable to ensure that it meets the needs of the present without compromising the ability of future generations to meet their own needs." Ibid.

26 "The Kyoto Protocol is an international agreement linked to the United Nations Framework Convention on Climate Change, which commits its Parties by setting internationally binding emission reduction targets.", "Kyoto Protocol", http://unfccc.int/ kyoto_protocol/items/2830.php, (Erişim Tarihi 13 Şubat 2016). 
görüşleri ağırlık kazanmaya başlamışırı. ${ }^{27}$ Örneğin, ABD’de, iklim değişikliğinin yerel olarak iklim olaylarında aşırılık gibi etkileri olacağı, uluslararası olarak da, ABD için stratejik önemi olan ülkelerdeki problemler gibi, ABD’nin ulusal çıarlarına karşı tehditler oluşturabilecek, daha geniş çaplı sorunların ortaya çıkabileceği görüşü egemen olmaya başlamıştır. ${ }^{28}$

Bu dönemde ayrıca, bir önceki dönemdeki kömüre yöneliş azalmış ve petrol ve gaza yönelim istikrarlı bir şekilde artarken kömür tüketimi neredeyse yatay seyretmiştir (Tablo 1). OECD ve nonOECD’nin kömür tüketiminde bir önceki dönemde görülen hızlı artışlar yavaşlamış ve non-OECD'de biraz daha hızlı olmak üzere, tüketim ya hiç artmamış ya da çok az artmıştır. Kömür tüketimini en fazla artıran ülkelerin başını 1986-1998 arasındaki 243,5 Mtep'lik artışla yine Çin çekmiş, ABD 110,7 Mtep'lik artışla ikinci sırada yer almıştır. En büyük azalma ise SSCB (-173,3 Mtep) ile AB'de (-165.7 Mtep) görülmüştür.

\section{8-2014 Dönemi}

1998’den günümüze kadarki dönem III. ve IV. Petrol Krizlerinin yaşandığı ve buna paralel olarak enerji jeopolitiğinin şiddetlendiği ikinci dönemdir. Bu dönemde ABD'de petrol ve gaz; Çin'de ise kömür üretim eğiliminde çok ciddi değişimler görülmüştür.

Varil başına petrol fiyatları 1998'de 12,72 \$ iken, bu tarihten sonra sürekli artarak 2008'de 106,94 \$ ile ilk zirvesini yapmıştır (Şekil 1). Daha sonra 2009'de 61.67 \$’a düşmüş ve tekrar artarak 2011 'de 111,26 \$ ile ikinci zirvesini yapmıştır; o günden bu yana da düşüş devam etmektedir. 19731986 arasında 9 kat artan petrol fiyatları bu sefer 11 kat artmıştır. İkinci jeopolitik dönemdeki petrol fiyatları enflasyondan arındırılmış 2014 sabit fiyatlarıyla ilkinden daha da yüksek olmuş; 1973-1986 dönemi zirvesi 1980'de 105,81 \$ olarak gerçekleşirken, 1998-2014 dönemi zirvesi 2011'de 117,09 \$ olmuştur. Bunun başlıca nedeni ikinci jeopolitik dönemin ilkine göre daha şiddetli geçmesidir.

İlkinde olduğu gibi, bu sefer de ABD’nin petrol üretimindeki düşüş enerji jeopolitiğinin gerginleşmesinin önemli bir sebebi olmuştur (Şekil 2). 1984'te 10,509 milyar varil/gün üretimle 1970 'ten sonraki ikinci zirvesine ulaşan ABD petrol üretimi, bu tarihten sonra sürekli olarak düşmektedir. Bu dönemde tüketim de arttığından 1985'te \%67,3’e kadar yükselen yerli üretimin tüketimi karşılama oranı da hızlı bir düşüş içerisine girmiştir. 1998'de ABD günlük petrol üretimi 8,011 milyar varil, tüketim ise 18,917 milyar varil olarak gerçekleşmiş ve yerli üretimin tüketimi karşılama oranı $\% 42,3$ olmuştur. İlerleyen yıllarda, ABD petrol üretimi ve tüketimi düşüş trendi içine girmiş ve 2007 'de üretim 6,860 milyar varil tüketim ise 20,687 milyar varil olarak gerçekleşmiştir. $\mathrm{Bu}$ tarihten sonra ciddi bir trend değişikliği gözlenmiş ve üretimin sürekli artıp tüketimin sürekli azalması neticesinde yerli üretimin tüketimi karşılama oranı 2006 'da $\% 33$ iken, günümüzde $\% 61,2$ 'ye kadar yükselmiştir. ABD'nin bu başarısının altında, eğimli ve yatay sondaj (inclined and horizontal drilling) ve hidrolik çatlatma (hydrocracking) gibi iki yeni teknolojiyi geliştirerek kaya petrolü (shale oil) ve kaya gazı (shale gas) gibi konvansiyonel olmayan hidrokarbon üretimini artırması yatmaktadır. Bir yandan alternatif kaynaklar sayesinde yerli enerji üretimini artıran ABD, diğer yandan az da olsa tüketimi azaltarak enerji arzını daha güvenilir hale getirmiştir.

27 Dalby, "Environmental Insecurities", s.5073; Joshua W. Busby “Climate Change and National Security: An Agenda for Action”, Council of Foreign Relations (CFR), No.32, Kasım 2007, s.4-5.

28 Kenneth T. Broda-Bahm, "Finding Protection in Definitions: The Quest for Environmental Security”, Argumentation and Advocacy, Cilt 35, 1999, s.59-70; Busby, "Climate Change and National Security”, s.26. 
Şekil 3 Dünya Fosil Yakıt Tüketimi, 1965-2014

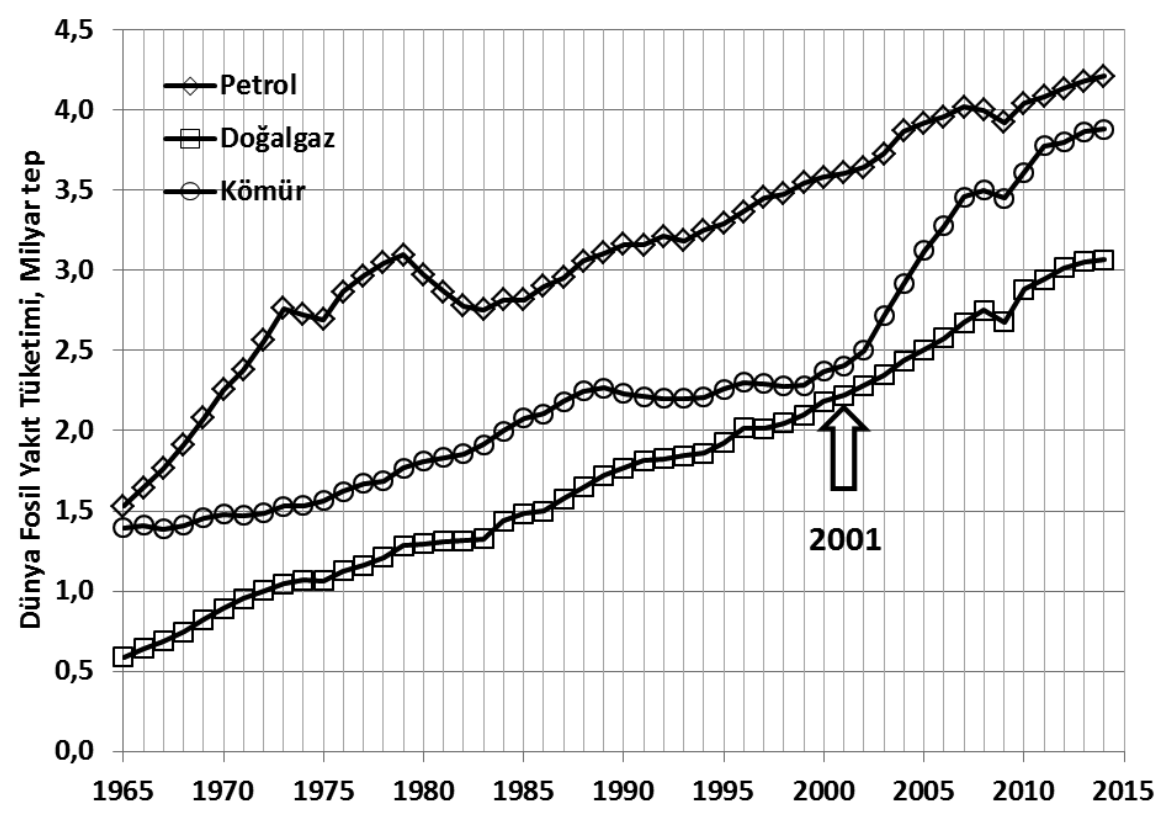

Dünya ülkelerinin genelde başvurduğu alternatif kaynak ise, ilk Petrol Krizi döneminde olduğu gibi, bu sefer de komür olmuştur (Şekil 3). 1998-2014 arasında dünya enerji tarihinde belki de hiçbir kaynakta görülmemiş şekilde, kömür önemli bir trend değişikliği geçirmiş ve tüketim değerleri 2001'den sonra 2279,3 Mtep’ten yukarıya doğru, hızla tırmanmaya başlamıştır (Tablo 1). Birçok uzman geçmiş trendleri izleyerek doğal gazın yükselişini sürdüreceği ve özellikle elektrik santrallerinde kömürün yerini alacağı öngörüsü ile "gas and power" adını verdikleri bu dönemde, doğal gazın toplam dünya enerji tüketimi içindeki payının artışılla 2001'de kömürün eğrisini keserek petrolden sonra ikinci sıraya yerleşmesini bekliyordu. Fakat bu gerçekleşmedi ve 1999'a kadar aşağı yukarı 2281,8 Mtep civarında kalan kömür tüketimi, petrol fiyatları arttıkça, günümüzde 3881,8 Mtep’e kadar yükseldi. İlkinde olduğu gibi, hızla artan petrol fiyatları nedeniyle petrol kömürle ikame edilmekte, petrol tüketimi de düşmektedir. 2007'de 4017,3 Mtep'e kadar çıan petrol tüketimi, 2009'da 3922,9 Mtep’e düşerek, kriz öncesi trende benzer bir şekilde devam etmektedir. Dünya doğal gaz tüketimi ise, bütün bu olaylardan hemen hiç etkilenmeden, 1965'ten itibaren, lineer artışını sürdürmektedir.

Kömür tüketimindeki trend değişikliği bazı ülkeler ve bölgelerde diğerlerine göre çok daha keskin olmuştur (Tablo 1). Non-OECD ülkelerinde \%140'lık bir artışla 1998'deki 1176,9 Mtep'den 2014'te 2829,3 Mtep'e çıan kömür tüketimi OECD ülkelerinde aynı dönemde 1102,4 Mtep'ten 1052,5 Mtep'e düşmüş, fakat önce 2007'ye kadar \%10'luk bir artışla 1215,8 Mtep'e çıkmış, daha sonra düşüşe geçmiştir. Non-OECD ülkelerinin kömür tüketimindeki bu hızlı artış, başlıca Çin'den kaynaklanmaktadır. 1965'ten beri, dünya kömür tüketiminde ilk sırada yer alan Çin, 1998-2014 arasında tüketimini \%140 artırarak 1176,9 Mtep'ten 2829,3 Mtep’e çıkarmıştır. Çin, günümüzde dünya kömür üretiminin $\% 46,9$, tüketiminin ise $\% 50,5$ 'sını tek başına gerçekleştirmektedir. Kömür tüketiminde Çin'i sırasıly ABD $(\% 11,7)$, Hindistan $(\% 9,3)$ ve $A B(\% 7,0)$ izlemektedir. Kömür tüketiminde 1988'e kadar AB'den sonra üçüncü sırada olan ABD, bu tarihte 500 Mtep civarında bir tüketim ile $\mathrm{AB}$ eğrisini keserek ikinci sıraya yükselmiştir. $\mathrm{ABD}$ kömür tüketimi 2007’ye kadar 
artışını sürdürerek 573,3 Mtep’e yükselmiş fakat bu tarihten sonra kaya gazı ve kaya petrolünün devreye girmesiyle sürekli düşerek 2014'te 453,4 Mtep’e gerilemiştir. Kısacası, III. ve IV. Petrol Krizleri döneminde ortaya çıkan enerji arz güvenliğini sorununu Çin kömür ikamesiyle, ABD ise kaya petrolü ve kaya gazı sayesinde teminat altına almaya çalışmışlardır. ${ }^{29} 2005$ 'e kadar dünyanın en büyük ikinci enerji tüketicisi konumunda bulunan $\mathrm{AB}$ ise, enerji verimliliğinde sağladığı gelişmelerle, birincil enerji tüketiminin önceleri artış hızında, daha sonra da miktarında ciddi düşüşler sağlamıştır. AB'nin birincil enerji tüketimi 2006'da 1833,8 Mtep'ten, 2014'te 1611,4 Mtep'e kadar sürekli olarak düşmüş, ABD ile arasında 1986'da 125,5 Mtep fark varken 2014'te bu fark 687,4 Mtep'e kadar çıkarmıştır.

1998-2014 döneminde enerji jeopolitiğinde yaşanan gelişmelerin dünya ekonomi ve siyasetindeki etkileri 1973-1986 dönemine göre çok daha fazla olmuştur. 1991'de Sovyetlerin dağılmasıyla birlikte, Soğuk Savaş’ın sona ermesinin ardından ortaya çıkan yeni dünya düzeninde güvenlik algıları değişmiş, ${ }^{30}$ özellikle büyük küresel güçlerin Avrasya ${ }^{31}$ ve Ortadoğu ${ }^{32}$ stratejileri yeniden belirlenmiş ve uluslararası ilişkilerde "medeniyetler çatışması" "33 kavramı ön plana çıkmaya başlamıştır. 20. yüzyıl sonlarında ortaya çıkan bu görüşlerin hayata geçmesi ise 21. yüzyıl başlarında New York'taki ikiz kulelere yapılan saldırıyla birlikte gözlenmeye başlanmıştır. ABD topraklarında ilk kez rastlanan bu tarihi olaydan sonra, bütün dünyada ülke güvenliği ön plana çıkmış ve özgürlükleri kısma pahasına terörizme karşı ciddi önlemler alınmaya başlanmıştır.

19 Mart 2003'te, jeopolitik gelişmeler Ortadoğu' ya sıçrayarak, ABD ve müttefikleri tarafından Irak'ı Özgürleştirme Operasyonu (Operation Iraqi Freedom) başlatılmıştır. Büyük Ortadoğu Projesi ve Arap Baharı'nın ardından başlayan olaylar, ABD kuvvetlerinin Aralık 2007'de Irak'ı terk etmeye başlamalarından sonra günümüzde, Suriye özelinde bütün şiddetiyle devam etmektedir. 2008'de Rusya'nın müdahalesiyle başlayan Güney Osetya Savaşı petrol fiyatlarını aşırı yükselterek, ABD'den başlayarak bütün dünyaya yayılan ekonomik krize neden oldu. Küresel Finans Krizi, 1930 Büyük Bunalımı́ndan beri dünyanın yaşadığı en büyük küresel çaplı ekonomik kriz olarak tarihe geçti. Birçok uluslararası firmanın kapandığı, tüketici varlıklarının trilyonlarca dolar kayba uğradığı, ekonomik faaliyetlerin önemli ölçüde kan kaybettiği ve borçlanmaların tırmandığı krizin etkileri hala devam etmekte olup, başta Çin olmak üzere, birçok ülkede kalkınma hızları önemli ölçüde düşmektedir. 2014'te başlayan Ukrayna Krizi jeopolitik gelişmelerin Avrupa’nın sınırlarına dayanmasına neden oldu. Ukrayna'nın bölünerek Kırım'ın Rusya'ya ilhakıyla AB Rusya'ya ekonomik ambargo koydu. 1996'dan beri İran’a karşı ABD tarafından sürdürülen ambargo ise, iki tarafın yakınlaşmasıyla yumuşatıldı. Arktik bölge ile Doğu Akdeniz ve Kuzey Çin Denizi’ndeki zengin hidrokarbon potansiyeli için özellikle, münhasır ekonomik bölge sınırları konusunda başlatılan çatışmalar da halen devam etmektedir.

29 Robert D. Kaplan, “The Geopolitics of Shale”, 19 Aralık 2012, http://www.businessforum.com/STRATFOR_ Geopolitics-Shale.pdf (Erişim Tarihi 16 Şubat 2016), s.1-4.

30 Ronald D. Asmus, Richard L. Kugler ve F. Stephen Larrabee, “Building a New NATO”, Foreign Affairs, Cilt 72, No.4, Eylül/Ekim 1993, s.28-40.

31 Zbigniew Brzezinski, “A Geostrategy for Eurasia”, Foreign Affairs, Cilt 76, No.5, Eylül/Ekim 1997, s.50-64; Lawrence Freedman, "Order and Disorder in the New World", Foreign Affairs, Cilt 71, No.1, 1991, s.20-37.

32 Bernard Lewis, "Rethinking the Middle East", Foreign Affairs, Cilt 99, Sonbahar 1992, s.99-118; Bernard Lewis, "The West and the Middle East", Foreign Affairs, Cilt 76, No.1, Ocak/Şubat 1997, s.114-130; Robin Wright, "Islam, Democracy and the West", Foreign Affairs, Cilt 72, No.3, Yaz 1992, s.131-145.

33 Samuel P. Huntington, “The Clash of Civilizations?”, Foreign Affairs, Cilt 72, No.3, Yaz 1993, s.22-49. 


\section{Farklı İhtiyaçlar ve Yerli Kaynaklar}

Küresel iklim değişikliği konusunda uluslararası düzeyde yürütülen faaliyetlerin kapsam, içerik ve etkinliklerinin enerji jeopolitiği tarafından belirleniyor olmasının en temel nedeni, ülkelerin enerji ihtiyaçlarının birbirlerinden oldukça farklı olması ve ekonomik açıdan, mümkün olduğu kadar yerli kaynakları kullanmaya meyilli olmalarıdır.

Kyoto Protokolü görüşmeleri ve sonrasında doğal olarak, her ülke kendi ihtiyaçlarını gözönüne almış ve ona göre bir iklim değişikliği stratejisi belirlemiştir. Anlaşmayı ilk imzalayan ülkeler $A B$ ülkeleri olmuş, imza atmayan önemli ülkeler arasında $A B D$ ve Avustralya gibi gelişmiş ülkeler ile Türkiye gibi gelişmekte olan ülkeler yer almıştır. Çin ve Hindistan gibi hızlı kalkınan ve enerji tüketimlerini yerli kömürle sağlamak zorunda olan bazı ülkeler ise, salım azaltmak zorunda kalmadıklarından anlaşmayı imzalamakta sakınca görmemişlerdir. Ağırlıklı olarak jeotermal enerjiyi kullanan İzlanda, 55 ülke şartının yerine getirilerek anlaşmanın yürülüğe girmesinin sağlanması amacıyla Mayıs 2002'de, doğal gaza dayalı bir sisteme sahip olması nedeniyle salım konusunda hiçbir sorunu bulunmamasına rağmen, jeopolitik nedenlerle protokolü başlangıçta imzalamayan Rusya ise, \%55 şartının yerine getirilerek anlaşmanın yürürlüğe konulabilmesi amacıyla, Kasım 2004'te anlaşmayı imzalamışlardır. Nitekim anlaşma ancak 16 Şubat 2005 'te yürürlüğe girebilmiştir.

ABD'de Bush yönetiminin protokolü imzalamayı reddetmesinin temel nedeni, bir dünya hegemonik gücü olarak, enerji kaynaklarına olan hâkimiyetini yitirmek istememesidir. Bunun için, ülke ekonomisine hiç zarar vermeden enerji tüketiminin azaltılabileceğine ve bunun da fiyatlar üzerindeki baskıyı azaltacak olmasına rağmen, ekonominin gerileyeceği gerekçe gösterilmiştir. ${ }^{34}$ Üstelik bağlayıcılığı olan bir kota uygulamasına karşı çıkmasına rağmen, ABD 2013'te Kyoto hedeflerine ulaşmış oldu. ${ }^{35}$ En hızlı kalkınan ülkeler arasında sayılan Türkiye ise, haklı bazı gerekçelerle protokolü imzalamayı geciktirmiş, fakat $A B$ ’ye katılım süreci içerisinde, $A B$ ve uluslararası kuruluşlardan gelen yoğun baskılar üzerine, 5 Şubat 2009 'da protokolün imzalanmasını onaylamıştır. ${ }^{36}$ Türkiye, OECD ülkesi olması nedeniyle, UNFCCC 1992'de hem Ek-I hem de Ek-II listesine yerleştirilmişti. Fakat diğerleriyle kıyaslanınca Türkiye henüz endüstrileşme sürecini ve dolayısıyla kalkınmasını tamamlayamamıştı ve çok az SG üretiyordu. Türkiye, bu nedenleri öne sürerek Konvansiyona katılmayı reddetti. Daha sonra, 2001'de Marakeş'teki Conference of the Parties 7'da (COP 7) “özel durumu” nedeniyle, Ek-II listesinden çıkarıldı ve bunun üzerine UNFCCC’yi 189. taraf olarak, 24 Mayıs 2004'te imzaladı; fakat Kyoto Protokolü'nü, SG azaltım maliyeti ve uluslararası ticarette rekabet edebilirliğini azaltacağı gerekçesiyle 2009’a kadar imzalamadı.

Yukarıda ayrıntılarıyla izah edildiği gibi, petrol fiyatlarının aşırı yükselmesi karşısında, özellikle büyük ülkeler -çevreye ve küresel iklime zarar verme pahasına da olsa- kendi iç kaynaklarına yönelmektedir. ABD’nin, önce petrol tüketimini azaltarak yerli kaynakların tüketim içindeki payını artırması, daha sonra da kaya gazı ve kaya petrolü gibi yerli enerji kaynaklarını devreye sokması, başta Çin olmak üzere, kömür rezervlerine sahip olan ülkelerin de petrolü kömürle ikame etmesi, Türkiye’nin kalkınmasını engelleyeceği gerekçesiyle Kyoto Protokolü’nü imzalamakta tereddüt etmesi ve tek yerli fosil yakıt kaynağı olan kömüre ağırlık vermesi bu girişimlerin en güzel örnekleri

34 Richard N. Haass, “The Age of Nonpolarity: What Will Follow U.S. Dominance”, Foreign Affairs, Cilt 87, No.3, Mayıs/ Haziran 2008, s.53; Cohen, Geopolitics: The Geography of International Relations, s.214.

35 Cohen, Ibid.

36 Erkan Erdoğdu, “Turkish Support to Kyoto Protocol: A Reality or Just an Illusion”, Renewable and Sustainable Energy Reviews, Cilt 14, No.3, Nisan 2010, s.1111. 
arasındadır. ${ }^{37}$ Çok sınırlı enerji kaynaklarına sahip olan AB ise, yenilenebilir kaynaklara ağırlık vererek ve enerji verimliliğini artırarak, dışa bağımlığı azaltma ve küresel iklim değişikliğine duyarlılık konusunda dünyada öncü olma stratejisi izlemektedir.

Ülkelerin enerji ihtiyaçları, ekonomik, sosyal ve siyasi yapılarına göre, Maslow'un İhtiyaçlar Hiyerarşisi'ne oldukça benzer bir yapı içinde belirlenmektedir. Bilindiği gibi, Maslow'un İhtiyaçlar Piramidi, insanoğlunun ihtiyaçlarını alttan üste doğru; "fizyolojik" (physiological), "korunma" (safety), "sevgi ve aidiyet" (love/belongingness), "saygl/itibar" (esteem), ve "kendini gerçekleştirme" (selfactualization) şeklinde sıralamıştır. ${ }^{38}$ İnsanlar ihtiyaçlarını karşılamada, piramidin altından üstüne doğru gitmekte ve alt basamaktaki ihtiyaçlar karşılanmadan genellikle üst basamaktakilere geçilememektedir.

Christoph W. Frei de, Maslow'un çalışmasını esas alarak, onun piramidini enerji ihtiyaçlarına uyarlamıştır. Buna göre, enerji ihtiyaçları da Maslow Piramidine benzer bir şekilde, "ticari enerjiye erişim" (access to commercial energy), "arz güvenliği" (security of supply), "maliyet verimliliği" (cost efficiency), "doğal kaynak verimliliği" (natural resource efficiency) ve "sosyal uygunluk" (social acceptability) gibi bazı tabakalardan oluşmaktadır. ${ }^{39}$ Makalesinde, "Kyoto Protokolü’nün enerji arz güvenliğine kurban edilip edilmediği” sorusuna cevap arayan Frei, sonuçta, "Kyoto Protokolünün arz güvenliğine kurban edilebileceğini” söyleyerek, çevrecilerin enerji fakirliği (energy poverty) konusuna öncelik verip amaçlarına ulaşmak için mücadele etmeleri önerisinde bulunmaktadır. Dolayısıyla, enerji ihtiyaçları konusundaki en öncelikli konu "ticari enerjiye erişim" olmalıdır ve ancak bu halledildikten sonra üst basamaklara tırmanılarak "arz güvenliği” ve "maliyet verimliliği”ne geçilebilir. Sosyal açıdan kabul edilebilirlik, çevre ve iklim değişikliği gibi konular ise piramidin en üst basamaklarında yer almaktadır. Piramidin en üstündeki üç basamak sürdürülebilir kalkınmanın ihtiyaçlarının dengelenerek birlikte ele alınmasını öngörmektedir. Frei'ya göre, tarihsel olarak incelendiğinde, 1970’lerin sonlarına kadar, sanayileşmiş ülkeler, maliyetlerin içselleştirilmesi (internalization of external costs) gibi "doğal kaynak verimliliği” konularına odaklanmışlar, ancak 1980’lerin sonlarında, özellikle sanayileşmiş ülkelerde "sosyal uygunluk" gündeme gelebilmiştir.

Dolayısıyla, birbirlerini ikame edebilme ve enerji karışımlarının büyük çoğunluğunu oluşturmaları açılarından ülke fosil yakıt rezervlerinin enerji ihtiyaçlarının belirlenmesinde büyük önem taşıdığı ve bu önemini uzunca bir süre daha koruyacağı ortadadır. Ülkelerin ve bölgelerin enerji ihtiyaçları ve bu ihtiyaçlarını karşılayacak yerel kaynaklar ile ülke koşullarına göre oluşturulan strateji ve politikaları ile onları uygulama imkân ve kapasiteleri birbirlerinden oldukça farklıdır. Örneğin, fosil yakıt üretimi ve tüketimi arasındaki fark; 2014 yılında, Orta Doğu'da 1.060 Mtep, Afrika'da 341 Mtep, Güney ve Orta Amerika'da 102 Mtep iken, başka bir deyişle üretim fazlası verirken, fosil yakıt bütçeleri; Asya-Pasifik'te -1.219 Mtep, Kuzey Amerika'da -95 Mtep, Avrupa ve Avrasya'da -66 Mtep açık vermektedir. Ülkeler bazında ise, en çok üretim fazlası veren beş ülke; Rusya Federasyonu (624 Mtep), Suudi Arabistan (401 Mtep), Avustralya (234 Mtep), Endonezya (220 Mtep) ve Katar (193 Mtep); en fazla açık veren beş ülke ise; Avrupa Birliği (873 Mtep), Çin (473 MTep), Japonya (424 Mtep), ABD (289 Mtep), Hindistan (273 Mtep) ve Güney Kore (235 Mtep) olarak ortaya çıkmaktadır.

Ülkelerin fosil yakıt üretim ve tüketimlerinin çeşitli nedenlerle rezervleri ile orantılı gerçekleşmediği, bazı ülkelerin, toplam rezervden aldıkları paya göre daha hızlı, bazılarının da daha

37 Volkan Ş. Ediger, TKİ ve Kömürün Tarihçesi ile Kömür Stratejileri, Ankara, TKİ Kurumu Yayınları, 2. Baskı, 2015, s.1-497; Volkan Ş. Ediger (der), Türkiye’de İklim Değişikliği ve Sürdürülebilir Enerji, İstanbul, ENIVA Yayınları, 2013, s.1-146.

38 Abraham Maslow, “A Theory of Human Motivation”, Psychological Review, Cilt 50, No.4, 1943, s.370-396.

39 Christoph W. Frei, “The Kyoto Protocol-A Victim of Supply Security? or: If Maslow were in Energy Politics”, Energy Policy, Cilt 32, 2004, s.1253-1254. 
yavaş bir üretim veya tüketim politikası izledikleri bilinmektedir. Bu nedenle, fosil yakıt rezerv sıralamasını petrol, doğal gaz ve kömür bazında değerlendirmek daha anlamlı olmaktadır. Tablo2'de görülebileceği gibi, dünya genelinde diğerlerine göre bariz bir şekilde çok daha fazla fosil yakıt rezervine sahip iki ülke \%15,5 payla $A B D$ ve \%13,4 payla Rusya Federasyonu'dur (RF). \%3,9 ile \%7,7 arasındaki ikinci kategoride, sırasıyla Çin, İran, Venezuela, Suudi Arabistan, Avustralya ve Hindistan bulunmaktadır. Daha alttaki 7 ülkenin rezervleri ise \%2,9 ile \%2,0 arasında değişmektedir. Fakat bu liste toplam fosil yakıt rezervi sıralaması olup, rezervleri en büyük üç ülke, sırasıyla, petrolde Venezuela (46,6 Milyar Tep), Suudi Arabistan (36,7 Milyar Tep) ve Kanada (27,9 Milyar Tep); doğal gazda İran (30,6 Milyar Tep), RF (29,8 Milyar Tep) ve Katar (22,1 Milyar Tep); kömürde ise ABD (115,3 Milyar Tep), RF (68,7 Milyar Tep) ve Çin (58,9 Milyar Tep) olarak belirmektedir.

Tablo 2 Fosil Yakıt Rezerv Sıralaması, 2014

\begin{tabular}{|l|l|r|r|r|r|r|}
\hline Sıralama & Ülke & $\begin{array}{c}\text { Petrol, } \\
\text { MTep }\end{array}$ & $\begin{array}{c}\text { Doğal Gaz, } \\
\text { MTep }\end{array}$ & $\begin{array}{c}\text { Kömür, } \\
\text { MTep }\end{array}$ & $\begin{array}{c}\text { Fosil Yakıt, } \\
\text { MTep }\end{array}$ & Pay, \% \\
\hline $\mathbf{1}$ & Amerika Birleşik Devletleri & 5,888 & 8,792 & 115,265 & 129,946 & 15,5 \\
\hline $\mathbf{2}$ & Rusya Federasyonu & 14,132 & 29,379 & 68,699 & 112,211 & 13,4 \\
\hline $\mathbf{3}$ & Çin & 2,521 & 3,113 & 58,900 & 64,534 & 7,7 \\
\hline $\mathbf{4}$ & İran & 21,676 & 30,618 & & 52,294 & 6,2 \\
\hline $\mathbf{5}$ & Venezuela & 46,576 & 5,023 & 0,319 & 51,918 & 6,2 \\
\hline $\mathbf{6}$ & Suudi Arabistan & 36,676 & 7,350 & & 44,026 & 5,2 \\
\hline $\mathbf{7}$ & Avustralya & 0,442 & 3,364 & 37,833 & 41,639 & 5,0 \\
\hline $\mathbf{8}$ & Hindistan & 0,763 & 1,284 & 38,900 & 40,947 & 4,9 \\
\hline $\mathbf{9}$ & Kanada & 27,875 & 1,827 & 3,352 & 33,054 & 3,9 \\
\hline $\mathbf{1 0}$ & Katar & 2,694 & 22,075 & & 24,770 & 2,9 \\
\hline $\mathbf{1 1}$ & Kazakistan & 3,932 & 1,355 & 18,367 & 23,654 & 2,8 \\
\hline $\mathbf{1 2}$ & Irak & 20,243 & 3,229 & & 23,472 & 2,8 \\
\hline $\mathbf{1 3}$ & Avrupa Birliği & 0,775 & 1,344 & 20,322 & 22,440 & 2,7 \\
\hline $\mathbf{1 4}$ & Güney Afrika & & & 20,104 & 20,104 & 2,4 \\
\hline $\mathbf{1 5}$ & Birleşik Arap Emirlikleri & 12,976 & 5,482 & & 18,458 & 2,2 \\
\hline $\mathbf{1 6}$ & Ukrayna & & 0,574 & 16,408 & 16,982 & 2,0 \\
\hline $\begin{array}{l}\text { Dünya } \\
\text { Toplamı }\end{array}$ & & 239,840 & 168,366 & 431,577 & 839,784 & 100,0 \\
\hline
\end{tabular}

Dünya toplam fosil yakıt rezervlerinin yaklaşık yarısı $(\% 51,4)$ kömürden, \%28,6’sı petrolden, \%20'si ise doğal gazdan oluşmaktadır. Dolayısıyla, rezervlerin yaklaşık yarısı kömür, diğer yarısı da sektörel açıdan birbirleriyle oldukça bağlantılı petrol ve doğal gazdan, yani hidrokarbonlardan oluşmaktadır. Hidrokarbonlarda herhangi bir güvenlik sorunu çıktığı zaman kömüre başvurulmasının temel nedeni de budur. Örneğin, Çin ve Hindistan 1998'den beri süregelen jeopolitik dönemde, hidrokarbonlarla kıyaslanamayacak ölçüde, ülkeleri için önemli olan yerli kömüre ağırlık vermişlerdir. 2014'te dünya kömür üretiminin \%46,9'u Çin'de gerçekleşirken, diğer ülkelerin sıralaması şöyledir: $\operatorname{ABD}(\% 12,9)$, Endonezya $(\% 7,2)$, Avustralya $(\% 7,1)$, Hindistan $(\% 6,2)$, RF $(\% 4,3)$ ve $A B(\% 3,9)$. Yerel kömür kaynaklarının oluşturacağı ekonomik menfaatler, Avustralya ve ABD gibi ülkelerin Kyoto Protokolü’nün imzalanmasında bu kadar isteksiz davranmalarının da esas nedenidir. ${ }^{40}$

40 Hillard G. Huntington ve Stephen P. A. Brown, “Energy Security and Global Climate Change Mitigation”, Energy Policy, Cilt 32, 2004, s.715. 


\section{Uygulamalarda Devlet ve Özel Sektörün Rolü}

Kyoto Protokolü iklim değişikliğine karşı iki farklı eylem geliştirmiştir. Bunlardan bir tanesi "mitigation" denilen, sera gazlarının artması nedeniyle atmosferde biriken ısının sabitleştirilmesi ve azaltılması. İkincisi de, hâlihazırda ortaya çıkmış iklim değişikliklerine uyum sağlanması (adaptation). SG salım azaltımının sağlanması için, Protokol, ülkelerin kalkınmışlık düzeylerine göre farklı hedefler belirlemiştir ve bu hedeflere ulaşılabilmesi için gerekli maliyetlerin düşürülmesi amacıyla Temiz Kalkınma (Clean Development-CDM), Ortak Uygulama (Joint Implementation-JI) ve Salım Ticareti (Emissions Tradin -ET) gibi bazı piyasa mekanizmaları önermiştir. Bu mekanizmalar, taraflara, salım azaltımı ya da diğer ülkelerde atmosferdeki karbonun giderilmesi için düşük maliyetli olanaklar sağlamaktadır. ${ }^{41}$ Fakat salım azaltım hedeflerinin hayata geçirilmesi için devletler sorumlu kılınırken, mekanizmalar serbest piyasa mantığı içinde, piyasalarda gerçekleştirilecektir. Bu çelişik durum, çözüm için gerekli olan enerji verimliliği ve alternatif enerji kaynaklarının devreye sokulması gibi yüksek maliyetlerin kimin tarafından karşılanacağı konusunda ciddi sorunlar ortaya çıkarmaktadır. ${ }^{42}$

Küresel iklim değişikliği, gerçekte bir çevre sorunundan çok bir üretim sorunudur ve salımların azaltılması konusunda hiçbir teşvik mekanizması oluşturulmadan tonlarca fosil yakıtın üretilmesi ve tüketilmesini sağlayarak, küresel kapitalizm tarafından ortaya çıkarılmıştır. ${ }^{43}$ Matthew E. Kahn gibi neoklasikekonomistler, "Kapitalizm nasıliklim değişikliğineneden olduysa aynışekildeiklim değişikliğine uyum sağlamamız ve kalabalık gezegenimizi ortak paylaşmamız konusunda da bizlere yardımcı olacaktır" tezini savunmaktadırlar. ${ }^{44}$ Onlara göre, uluslararası serbest piyasalar geliştirilerek ve devletin müdahalesi asgari düzeyde tutularak iklim değişikliği konusunda başarılı olunabilecektir ve böylece -daha önce de birçok kez test edildiği gibi- iklim değişikliği konusunda ortaya çıkabilecek her türlü yeni şok serbest piyasa tarafından karşılanabilecektir. Hükümetlerin asıl görevi, yeşil ekonomiye geçişte gerekli olan inovasyosyonların etkinleştirilmesi ve yatırımların sağlanması olmalı; "oyunun kurallarını" belirlemek ve onları harfiyen uygulamakla sınırlı tutulmalıdır. Öte yandan, bilim adamları, özellikle çevre ekonomistleri de, status quo politikalarının değişmesine yönelik ve küresel yaklaşımları sağlayıcı çalışmalar yaparak, karbon vergileri, kirlilik permisi piyasaları gibi kamu politikaları geliştirmelidirler.

$\mathrm{Bu}$ görüşler teorik bazda uygun görünse de, uygulamalarda bu konuda birçok zorlukla karşılaşılmaktadır. Örneğin, 2005'ten beri gelişerek dünyanın en büyük SG salım ticareti sistemi olan AB Salım Ticareti Sistemi (EU Emissions Trading System-EU ETS), ülke sayısının 30'u, tesis sayısının 11.000 'i geçmiş olmasına rağmen yeterince başarılı olamamıştır. ${ }^{45} \mathrm{Bu}$ sistem, ayrıca karbondioksit $\left(\mathrm{CO}_{2}\right)$ salımını düşürmeyi başaramamış, aksine hızı yavaşlasa da artış devam etmiştir. ${ }^{46}$ Bunun başlıca nedeni, odak noktalarındaki farklılıklar sebebiyle devletler ve özel sektör arasında yeterinli uyumun sağlanamamış olmasıdır. Bu yapıllardan birinin kamunun, diğerinin ise şahsi memnuniyetinin peşinde olması nedeniyle, doğal olarak, doğrudan gelir elde etmelerini sağlamayan mekanizmaların hayata geçirilmesinde, serbest piyasa aktörleri temkinli davranmaktadır. Bu yüzden salım ticareti konusu genellikle spekülatörlerin eline geçmektedir.

41 "Kyoto Protocol”, http://unfccc.int/kyoto_protocol/mechanisms/items/2998.php, (Erişim Tarihi 15 Şubat 2016).

42 Stein Tonnesson, "The Case for a Proactive Indian and Chinese Approach to Climate Change and Energy Security", Strategic Analysis, Cilt 31, No.3, Mayıs 2007, s.439.

43 Örneğin, Dalby, “Environmental Insecurities”, s.5073-5079; Matthew E. Kahn, “The Geopolitics of Climate Change: An Economist's Perspective”, Political Geography, Cilt 37, 2013, s.53-55.

44 Kahn, Ibid.

45 “The EU Emissions Trading System (EU ETS)”, http://ec.europa.eu/clima/policies/ets/index_en.htm, (Erişim Tarihi 22 Şubat 2016).

46 Cohen, Geopolitics: The Geography of International Relations. 
Bu konudaki diğer önemli sorun da devletlerin mekanizma tercihi açısından özgür bırakılmamış olmalarıdır. Devletler kendi ülkelerine özgü mekanizmaları oluşturamamakta ve ülkelerin aleyhine olsa da dünya için en uygun olanı seçmek zorunda kalmaktadır. ${ }^{47}$ Öte yandan, mekanizma seçimi konusunda özgür olmayan devletler, uygulama konusunda tamamen kendi başlarına kalmaktadırlar. Hâlbuki sorun küreseldir ve çözüm de devletlerin dayanışması içinde küresel olmak zorundadır. ${ }^{48}$ Her ülkenin koşulları, hedefleri ve kapasitesi birbirinden çok farklıdır ve dolayısıyla çıkarları da farklı olacaktır. $\mathrm{Bu}$ nedenle, özellikle gelişmiş ülkeler insan kaynağı, teknoloji ve finansman konularında, gelişmekte olan ülkelere yardım ellerini uzatmalı ama uygulamalar ülke bazında belirlenebilmelidir. Bunun için, "devlet sınırlarının büyük çoğunlukla sabit olduğu, fakat coğrafya sınırlarının birbirini aştığı” gerçeği gözönünde bulundurulduğunda klasik devlet bakışının iklim değişikliğinin jeopolitikasını anlamak için yeterli olmayacağı görülecektir. ${ }^{49}$ Bu nedenle, devletler soruna birlikte bakmayı öğrenmeli, bilim adamlarının görevi de giderek kalabalıklaşan gezegenin ortak kullanımına yönelik olarak siyasileri ve politika yapıcılarını, ülke sınırları dışına çıkararak, olaya küresel açıdan bakabilmelerini sağlamak olmalıdır..$^{50}$

Devletlerin ortak bakışa sahip olamamasının başlıca nedeni, farklı ihtiyaçlar ve ihtiyaçların farklı karşılanma koşulları nedeniyle ülkelerin farklı strateji ve politikalar izliyor olmalarıdır. Normlar, değerler ve sistemler açısından bakıldığında birbirlerine oldukça benzeyen ülkeler bile, sırf bu nedenlerle bir noktada birleşememektedir. Örneğin, "Batı" kavramı içinde değerlendiren en önemli, her açıdan müttefik iki ülke olan $A B D$ ve $A B$ neden küresel iklim değişikliğine cevap verilmesi konusunda bir noktada uzlaşamıyor? Bu sorunun en makul cevabı, Tablo 2'de açıkça görüldüğü gibi, fosil yakıt rezervleri sıralamasında ABD \%15,5 payla (129,9 milyar tep) birinci sirada iken, AB'nin sadece $\% 2,7$ payla (22,4 milyar tep) 13 'üncü sırada yer alıyor olmasıdır. ABD, uzunca bir süre fosil yakıtları kullanmayı düşünürken, AB'nin yerli ve yenilenebilir kaynaklara ve enerji verimliliğine önem vermekten başka çaresi yok gibidir. Başta Almanya olmak üzere, bütün AB ülkeleri, uluslararası eylemlerin kaçınılmaz olduğunu görerek, iklim değişikliği konusunu kendilerinin yeni status quo'su yapmıştır. ${ }^{51}$

ABD başta olmak üzere, Çin ve Hindistan gibi ülkelerin de mutlaka işin içinde olmaları gerekmektedir; onlarsız çözüme ulaşmak imkânsızdır. Çin ve Hindistan iklim değişikliği tehdidini, kirli teknolojilerden uzaklaştıracak yeni teknolojilere tam destek vererek, yeni kalkınma stratejileri geliştirerek, bir siyasi bir avantaja dönüştürebilirler. Bu ülkeler, yeni leapfrog kalkınma stratejileriyle, sadece bilim ve teknolojinin geliştirilmesine katkı sağlamış olmazlar, aynı zamanda Batı Asya ve hatta Ortadoğu’da iklim değişikliği, enerji güvenliği ve siyasi istikrarın birlikte ele alınıp çözüme kavuşturulabileceğini de göstermiş olurlar. Bu da, farklı akademik disiplinlerden bilgilerin uyumlu bir kombinasyonu ile sağlanabilir. ${ }^{52}$

Son yıllardaki gelişmeler durumu daha da karmaşıklaştırmaktadır. Giderek hızlanan jeopolitik gelişmeler, hem enerji şirketlerinin yapılarında hem de devletlerin bakışlarında ciddi değişiklikleri zorlamışır. İki petrol krizi arasındaki düşük enerji fiyatlarından yararlanılarak, 1980'lerin ikinci

47 Huntington ve Brown, "Energy Security and Global Climate Change Mitigation”, s.716.

48 Busby, “Climate Change Blues”, s.113.

49 Dalby, "The Geopolitics of Climate Change", s.45.

50 Ibid, s.46.

51 Busby, “Climate Change Blues", s.115.

52 Stein Tonnesson, "The Case for a Proactive Indian and Chinese Approach to Climate Change and Energy Security", Strategic Analysis, Cilt 31, No.3, Mayıs 2007, s.417. 
yarısından itibaren İngiltere'de başlayarak tüm dünyaya yayılan, özelleştirmeye ağırlık verilerek serbest piyasa ekonomisinin güçlendirilmesine yönelik uygulamalar, özellikle 1998 sonrasında geçerliliğini büyük ölçüde yitirmiş bulunmaktadır. Yeni modelde devletin öncülügünde ve özellikle uluslararası ilişkilerdeki desteğinde "ulusal şampiyonlar" (national champions) ortaya çıkmaya başlamıştır. Yeni tarz şirketlerin hisselerinin çoğu devlete ait olmakla birlikte tam anlamılla bir özel sektör gibi, ticari mantıkla, bağımsız hareket edebilmektedirler. ${ }^{53}$ Küresel enerji şirketleri içinde Çin'in, China National Petroleum Corporation (CNPC); Hindistan'ın, Coal India; RF'nin, Gazprom; Malezya'nın, Petronas; Suudi Arabistan'ın, Saudi Aramco; Brezilya'nın, Petrobrass; Venezuela'nın, Petróleos de Venezuela, S.A. (PDVSA); İran'ın, İran Ulusal Petrol Şirketi (National Iranian Oil Company - NIOC) gibi şirketleri sayılabilir. Petrol şirketleri özelinde ise, ulusal petrol şirketlerinin (National Oil Company - NOC) dünya rezervlerindeki payı artarken, uluslararası petrol şirketlerininkiler (International Oil Company - IOC) azalmaktadır.

Gelişmeler sadece şirketlerle sınırlı kalmamış, devletler de enerji jeopolitikasını öne çıaran yeni yapılanmalara gitmişlerdir. 2011'de, ABD'de Dışişleri Bakanlığı bünyesinde “The Bureau of Energy Resources (ENR)” kurulmuştur. ${ }^{54}$ ENR'ın temel amacı, "yerel enerji patlamasını [kaya gazı üretiminin hızla artmasını] dünya genelindeki Amerikan çıkarlarını geliştirmek amacıyla jeopolitik bir araç haline getirerek ve ABD’nin ve küresel işbirlikleri ile uluslararası ortaklarının enerji güvenliğini artırmak” tır.

Avrupa Birliği'nde de, "French Dirigism" ya da "Colbertism" denilen "devletçilik" yeniden canlanmaya başlamıştır. ${ }^{55}$ Almanya'da 2014'te kurulan "Rohstoff Allianze of Germany (Resource Alliance)", 56 Fransa'da kurulan "Compagnie National des Mines de France (CMF)" 57 canlanan bu akımın vücut bulmuş halleri arasında sayılabilir. İkisinin de ortak amacı, özel sektörün ihtiyaç duyduğu ham maddelerin teminini, devletin de desteğiyle güvence altına almaktır. Son olarak, AB içinde de, "her Avrupalı için güvenli, sürdürülebilir, rekabetçi, makul fiyatlı enerji" Union” adıyla bir birlik kurulmuştur. Kömür ve Çelik Topluluğu'ndan (Coal and Steel Community) beri Avrupa'da ortaya çıkan en heyecanlı ve iddialı proje olarak değerlendirilen Energy Union, 28 $A B$ piyasasını birleştirerek, enerji bağımlılığını azaltmayı hedeflemektedir. $A B$, enerji arz güvenliği sorununu ABD'dekine benzer şekilde, bilim ve teknolojiyle çözmek için, Ufuk 2020 (Horizon 2020) kapsamında, araştırma ve inovasyona yaklaşık 80 milyar $€$ ayırmıştır.

AB’nin jeopolitik kaygıları dikkate almaya başlaması, birliğin enerji güvenliğinin teminat altına alınması için olumlu bir gelişme olarak değerlendirilmelidir. Zira konunun 2004 yılında gündeme gelmesine ve AB'nin Directorate-General for Transport and Energy (DG TREN) ${ }^{59}$ programı kapsamında Clingendael International Energy Programme (CIEP) tarafindan "Study on Energy Supply

53 “The Rise of State Capitalism”, 21 Ocak 2012, http://www.economist.com/node/21543160, (Erişim Tarihi 16 Ocak 2016).

54 “Bureau of Energy Sources”, http://www.state.gov/e/enr/, (Erişim Tarihi 16 Ocak 2016).

55 David Marsh, “France goes back to mining as source of national wealth”, 24 Şubat 2014, http://www.marketwatch.com/ story/france-goes-back-to-mining-as-source-of-national-wealth-2014-02-24, (Erişim Tarihi 21 Ocak 2016).

56 Christopher Ecclestone, “German Resource Alliance: The Rohstoff Allianz 'Circles the Wagons' to Make Investments”, 21 Mayıs 2015, http://investorintel.com/technology-metals-intel/german-circling-wagons/, (Erişim Tarihi 21 Ocak 2016).

57 “Compagnie nationale des mines de France”, 26 Ocak 2015, https://fr.wikipedia.org/wiki/Compagnie_nationale_ des_mines_de_France, (Erişim Tarihi 22 Şubat 2016).

58 "Secure, sustainable, competitive, affordable energy for every European."

59 DG TREN of the European Commission is now part of Directorate-General for Mobility and Transport (European Commission) Directorate-General for Energy (European Commission). 
Security and Geopolitics" ${ }^{60}$ başlıklı bir rapor yazılmasına rağmen, bu konu $\mathrm{AB}$ çevrelerinde günümüze kadar yeterince ilgi toplamamış, $\mathrm{AB}$ serbest piyasalara ve regülasyonlara daha fazla önem vermiştir. Söz konusu raporda, serbest piyasa mantığıyla çalışan Piyasalar ve Kurumlar (Markets and Institutions - M\&I) sistemi yerine, devletçiliğin ön plana çıktığı Bölgeler ve İmparatorluklar (Regions and Empires $\mathrm{R} \& \mathrm{E}$ ) sisteminin $A B$ 'nin enerji güvenliği için daha yararlı olacağı görüşü savunularak, mevcut sistemle "AB'nin giderek daha fazla enerji arz güvenliği riski” ile karşı karşıya kalabileceği uyarısı yapılmıştır. ${ }^{61}$ Benzer şekilde, Aurèlia Mañé-Estrada da, enerji jeopolitiğinde gözlenen değişiklikler nedeniyle, M\&I yaklaşımının başarısız olduğunu ve olmaya devam edeceğini savunmuştur. ${ }^{62}$ Ona göre, M\&I yaklaşımını esas alan enerji politikalarının uygulanması, güvenli enerji senaryoları oluşturamamaktadır ve özel sektör firmalarını daha da güçlendirerek, son günlerde artan petrol fiyatlarının temel sorumlusu haline gelmiştir; bir an önce R\&E yaklaşımı benimsenmelidir. ${ }^{63}$

\section{Sonuçlar ve Öneriler}

İklim değişikliği konusunda günümüze değin yeterince başarı sağlanamamasının başlıca üç nedeni bulunmaktadır. Bunlardan birincisi ve en önemlisi, dünya genelinde enerji jeopolitiğinin şiddetleniyor olmasıdır. Fosil yakıtlardan yeşil enerjiye geçiş dönemleri tarihsel perspektiften değelendirildiğinde, tam anlamıyla enerjide geçişin yaşandığı bu dönemde, jeopolitik kaygıların ön plana çıkması ve bu nedenle geçişin zorlaşması doğal kabul edilmelidir. Bu çalışmada, petrol fiyatlarındaki aşırı yükselmeler, enerji jeopolitiğinin şiddetlenmesinin piyasalara yansıması olarak değerlendirilmiş ve iklim değişikliği gibi konulardaki çalışmaların ancak fiyatların durgun olduğu, jepolitiğin sakin olduğu dönemlerde başarılı olabileceği görüşü öne sürülmüştür. Bunun yanı sıra, ülkelerin enerji ihtiyaçları ile onları karşılama imkân ve kabiliyetleri büyük önem taşımaktadır. Her ülkenin enerji sistemi genelde birbirlerine benzese dahi özelde önemli farklıklar göstermektedir. Buna karşılık, fosil yakıt rezervleriyle ifade edilebilecek ihtiyaçların karşılanma imkânları da birbirinden oldukça farklıdır. Her ne kadar sorun ortak ve küresel çaplı olsa da, bu şartları tek bir noktada birleştirmek imkânsız görünmektedir. Kalkınmışlık düzeyine bağlı olarak, bazı ülkeler temel ihtiyaçlarını karşılamaya çabalarken, bazıları daha lüks sayılabilecek ihtiyaçlarla meşguldürler.

Atmosfere yapılan salım miktarları açısından ülkeler incelendiğinde, ülkelerin farklı durumları açık bir şekilde ortaya çıkmaktadır. 2014 itibarıyla atmosfere en fazla $\mathrm{CO}_{2}$ salımı yapan ülkelerin başında sırasıyla; 9761,1 Mton ile Çin, 5994,6 Mton ile ABD, 3705,0 Mton ile AB gelmektedir. Çin'in salım eğrisi, 2003'te ikinci sıradaki AB'nin eğrisini, 2005'te de birinci sıradaki ABD'nin eğrisini keserek ilk sıraya yükselmiştir. ABD ve AB'nin eğrileri 1982'ye kadar birbirlerine oldukça paralel bir şekilde ilerlerken, bu tarihten sonra araları açılmaya başlamış ve 1982'de 354,3 Mton olan fark, 2014'te 2289,6 Mton’a yükselmiştir. Bu durum, Batı ülkeleri arasındaki enerji ve iklim değişikliği politikalarındaki farkı açıkça göstermektedir. Bu ilk üç ülkenin ardından, sırasıyla Hindistan (2088,0 Mton), Rusya Federasyonu (1657,2 Mton) ve Japonya (11945,8 Mton) gelmektedir. Fakat toplam miktar yerine, ülkelerin sosyo-ekonomik kalkınma düzeyini daha iyi yansıtması bakımından kişi başına düşen $\mathrm{CO}_{2}$ salım miktarlarına bakıldığında oldukça farklı bir tablo ortaya çıkmaktadır (Şekil 4). Dünya ortalamasının 2014 yılında 4,9 Ton olduğu kişi başına düşen salım miktarı, ABD'de 18,8 Ton, Rusya

60 Study on Energy Supply Security and Geopolitics.

61 Ibid, s.85.

62 Aurèlia Mañé-Estrada, "European Energy Security: Towards the Creation of the Geo-Energy Space”, Energy Policy, Cilt 34, 2006, s.3773-3774

63 Ibid, s.3776, 3786 . 
Federasyonu'nda 11,6 Ton, Japonya'da 10,6 Ton, Avrupa Birliği'nde 7,3 Ton, Çin'de ise 7,1 Ton olarak gerçekleşmiştir. Dünyanın en büyük enerji tüketicisi olan Çin, kişi başına salım açısından dünyada dördüncü sırada bulunmaktadır.

Şekil 4 Büyük Ülkelerin Kişi Başına Düşen CO $_{2}$ Salımı, 1965-2014

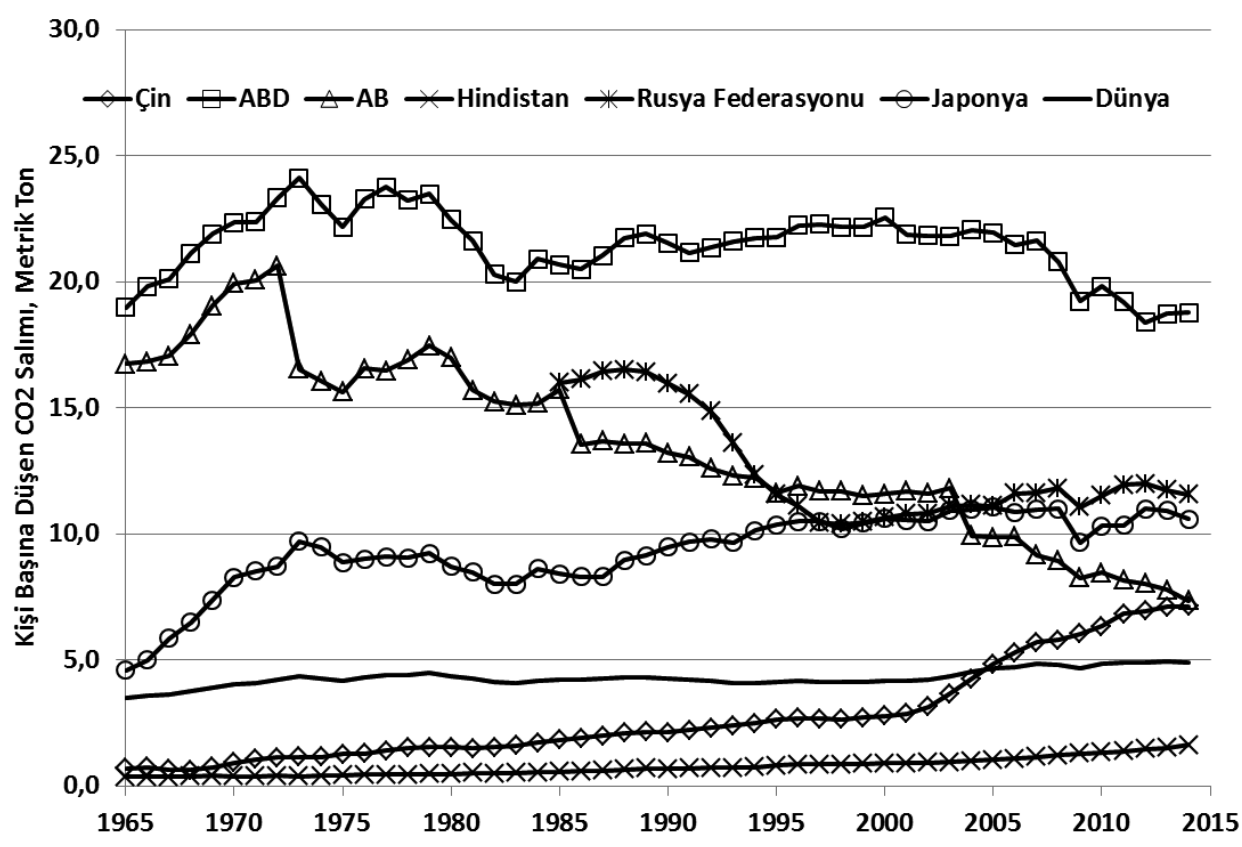

Dönemler arasında devletler ve şirketlerin yapılanmalarında da ciddi değişiklikler söz konusudur. Genelde, devletin ve özel sektörün rolü ve sorumluluğu, iklim değişikliği konularında belirli dengesizlikler oluştursa da, durgun dönemlerde gelişen piyasalar, jeopolitik dönemlerde yerlerini devletçiliğe bırakmakta, ülke güvenliği piyasaların serbestliğinden daha ön plana geçmektedir. Aslında, devletler için iklim değişikliği konusunda bir şeyler yapmak, onların yumuşak güçlerini öne çıkarmalarıaçısından önemlidir ve Çin gibi ülkeler dahi, genel olarak kabul edilmiş bulunan "yeşil yol" ile uluslararası camiada puan toplayabilirler. ${ }^{64}$ Örneğin, günümüze kadar iklim değişikliği konusundaki liderliğiyle $\mathrm{AB}$ büyük itibar kazanmış, uluslararası camiada saygınlığı artmıştır.

Özellikle 1998'de başlayıp günümüzde devam eden ikinci jeopolitik dönemde, dünya liderliği mücadelesinde önemli aşamalar kaydedilmiştir. Hegemonik güç olmanın önemli koşullarından biri olan enerjideki üstünlük ve kontrol kaabiliyeti, enerji jeopolitiğindeki gelişmeler neticesinde ABD'den Çin'e geçmiş bulunmaktadır. Kömür sayesinde dünyanın en büyük enerji tüketicisi konumuna yükselen Çin, dönemin başat gücü Büyük Britanya İmparatorluğu'nu 1901 yılında geçerek, dünyanın en büyük enerji tüketicisi olarak yeni başat güçlüğe soyunan ve bir asırdan daha fazla bir süre bu konumunu koruyan ABD'yi geçmiş bulunmaktadır. Birincil enerji tüketiminde yıllardır birbirlerine oldukça paralel gelişmeler izleyen RF, AB ve ABD eğrilerini, sırasıyla 1992, 2005 ve 2008'de kesen Çin toplam birincil enerjinin \%23'ünü tüketirken, \%17,8 ile ABD ikinci sıraya, \%12,5 ile AB de üçüncü sıraya düşmüş bulunmaktadır. Bu üç büyük ülkeyi sırasıyla, \%5,3 ile RF, \%4,9 ile Hindistan, \%3,5 ile Japonya izlemektedir.

64 Kahn, “The Geopolitics of Climate Change”, s.55. 
Enerji jeopolitiğindeki mücadelelerin nasıl sonuçlanabileceği ve gelecekte konuyla ilgili gelişmelerin neler olabileceğiyle ilgili varsayımlarda bulunabilmek için, uluslararası güç dengeleri ve enerji jeopolitiğiyle bu dengelerin ilişkilerini makul ihtimaliyet dâhilinde tahmin edebilmek gerekmektedir. Bilindiği gibi, dünyada en fazla tüketilen enerji kaynağı ile hegemonik güç arasında yakın bir ilişki bulunmaktadır. ${ }^{65} \mathrm{Bu}$ ilişki, Kömür Çağı’nda Büyük Britanya İmparatorluğu ile kömür arasında başlamış, Petrol Çağı’nda ABD ile petrol arasında devam etmiştir. Son günlerdeki gelişmeler, bu sefer tek bir yakıt yerine birden fazla yakıtın önemli olacağını göstermektedir. Eski konumunu korumak isteyen $\mathrm{ABD}$, teknoloji ve inovasyondaki üstünlügü sayesinde, konvansiyonel olmayan hidrobarkon kaynaklarına yönelmiş ve bu sayede petrol ve doğal gaz üretiminde önemli aşamalar kaydetmiştir. Başta Çin ve Hindistan olmak üzere, kömür zengini, gelişmekte olan birçok ülke, hızlı kalkınmalarını gerçekleştirebilmek için enerji ihtiyaçlarını kömürle karşılama politikası izlemektedirler. Rusya ise konvansiyonel doğal gazdaki üstünlügünü korumaktadır. Fakat devreye yeni girecek olan büyük hidrokarbon rezervi sahibi İran, Venezuela, Irak vb. gibi ülkelerdeki gelişmelerin, bu denklemi nasıl etkileyeceği sağlıklı bir şekilde tahmin edilememektedir. Ayrıca, geleceğin yakıtı olarak değerlendirilen hidrojen enerjisi ile güneş ve rüzgar gibi yenilenebilir enerji kaynakları ve ikinci kuşak biyoyakıt ile karbon tutma ve depolama dâhil olmak üzere, kömür gazlaştırmasındaki gelişmeler de önemli olacaktır. ${ }^{66}$

Bütün bu nedenlerden ötürü, küresel iklim değişikliği ile mücadele konusunu SG salımlarının sınırlaması kapsamının dışına çıkarılarak "sürdürülebilir kalkınma" çerçevesinde ele almakta büyük yarar bulunmaktadır. Gelecekte hâkim olacak yeni dünya düzeninin birden fazla gücün küresel ve bölgesel çapta egemen olduğu ve her birinin kendine özgü enerji sistemlerinin geliştiği bir düzene doğru gidiyor olması bu çerçevenin uygulamaya konulmasını kolaylaştırmaktadır. Bilindiği gibi, 20. yüzyıla gelindiğinde "çok kutuplu” (multipolar) bir sistem dünyaya hâkim olmuş, yaklaşık yarım asır sonra "iki kutuplu” (bipolar) bir sisteme, Soğuk Savaş sonrasında da "tek kutuplu” (unipolar) bir sisteme geçilmiştir. ${ }^{67} 2000$ 'li yıllarda, artık ABD’nin tek kutupluluğu sona ermiş ve dünya 21. yüzyılda "kutupsuz" (non-polar) bir dünya haline gelmiştir. Artık gerek sert ve gerekse yumuşak güçlerin bir veya iki elde toplanması beklenmemekte, muhtemel "çok kutuplu” (multipolar) bir dünyaya doğru gidilmektedir. Giovanni Grevi gibi uzmanlar bunu "kutuplararası" (interpolar) bir yapı olarak değerlendirmektedirler. ${ }^{68}$ Aslında, bir süredir çok kutuplu bir dünyanın özellikleri ortaya çıkmaya başlamış görünmektedir: Dünya nüfusunun yarısından fazlasına sahip olup, dünya gayri safi yurt içi hasılasının (GSYIHH) \%75'ini, savunma harcamalarının \%80'ini gerçekleştiren Çin, $A B$, Hindistan, Japonya, Rusya ve ABD küresel büyük güçler olarak ortaya çıkmıştır. ${ }^{69}$ Her ne kadar, şu anda özellikle askeri güç açısından ABD’nin karşısına çıkabilecek bir aktör yok ise de, ona meydan okuyan ülkelerden Çin ve Rusya, özellikle kalkınmakta olan petrol üreticisi ülkelere askeri yardım yaparak, onları askeri açıdan güçlendirerek önemli stratejik adımlar atmaktadır. ${ }^{70}$ Yeni güçlerin çoğunun Avrasyalı olması, dünya ekonomisinin ağırlık merkezinin Uzak Doğu’ ya kaymakta olduğunu göstermektedir. Zbigniew Brzezinski’nin de dediği gibi, artık Avrasya'yı kontrol eden,

65 Ediger, "Energy Transition Periods”, s.175-202; Ediger, Enerjide Yeni Dünya Düzeni ve Türkiye, s.1-62 ve oradaki referanslar; Kaplan, “The Geopolitics of Energy”, s.1-3.

66 Michael Klare, “The New Geopolitics of Energy”, The Nation, 19 May 2008, s.7.

67 Haass, "The Age of Nonpolarity", s.44-45.

68 Giovanni Grevi, The Interpolar World: A New Scenario, Paris, European Union Institute for Security Studies, Haziran 2009, s.1-39.

69 Haass, “The Age of Nonpolarity”, s.45.

70 Klare, “The New Geopolitics of Energy”, s.5. 
dünyayı da kontrol edecektir. ${ }^{71}$ Bunula birlikte, Ortadoğu Bölgesi bir önceki düzende olduğu gibi, bu yeni düzenin belirlenmesinde de önemli rol oynayacaktır. Enerji jeopolitiğinin 1998'den beri ısındığı, Türkiye'yi de içine alan Levant Bölgesi’nin, aynı dönemde, son 900 yılın iklimsel olarak da en sıcak dönemini geçiriyor olması, enerji jeopolitiği ve iklim değişikliği arasındaki ilginin ilginç bir boyutunu sergilemektedir. ${ }^{72}$

Son yıllarda önemli gelişmeler sağlanmasına rağmen, iklim değişikliği ve enerji jeopolitiği ilişkisinin, gerek küresel gerekse yerel düzeyde yeterince aydınlığa kavuşturulduğu söylenemez. Genellikle uluslararası ilişkiler çerçevesinde incelenen konu, kutuplar gibi yeni ortaya çıkan konularda disiplinlerarası çalışmalara muhtaçtır. Kutuplardaki buzların erimesi, bölgeyi, ticaret, ulusal güvenlik ve çevre açılarından rekabete açmış; bölge, bilimsel ve siyasi anlamda ilgi uyandırmaya başlamıştır. Ululararası hukuki ve siyasi sistemi derinden etkileyecek kadar önemli olan bu konu çerçevesinde, kutuplara erişim ve arama faaliyetleri yoğunlaşacağından, jeopolitik topluluğun, buraların sağlayacağı ticari fırsatların, küresel iklim değişikliği ve bölgenin makul ölçüler dışında bozulmaması konusunda ikna edici olması gerekmektedir. ${ }^{73}$ Hinrich Thölken'inde belirttiği gibi, "İklim değişikliği, 21. yüzyılın en büyük uluslararası politik meydan okumasıdır ve bu 20. yüzyılın ikinci yarısında ortaya çıan Soğuk Savaştan daha da büyüktür." ${ }^{34}$

71 Zbigniew Brzezinski, The Grand Chessboard: American Primacy and Its Geostrategic Imperatives, New York, Basic Books, 1997, s.31-125.

72 Benjamin I. Cook et.al., "Spatiotemporal Drought Variability in the Mediterranean over the Last 900 Years”, Journal of Geophysical Research: Atmospheres, 2016.

73 Charles K. Ebinger ve Evie Zambetakis, “The Geopolitics of Arctic Melt”, Bernice Lee (der), Tackling Resource Challenges in the 21st Century: Avoiding Worst Case Scenarios, Blackwell Publishing Ltd./The Royal Institute of International Affairs, 2009, s.1215, 1232.

74 Hinrich Thölken, "Politics and Policies”, British Medical Journal, Cilt 344, No.7849, 24 Mart 2012, s.34. 


\section{Kaynakça}

Afgan, N.H. et.al. "Sustainable Energy Development", Renewable and Sustainable Energy Reviews, Cilt 2, No.3, 1998, s.235-286.

Asmus, Ronald D., Richard L. Kugler ve F. Stephen Larrabee. "Building a New NATO”, Foreign Affairs, Cilt 72, No.4, Eylül/Ekim 1993, s.28-40.

Bauen, Ausilio. "Future Energy Sources and Systems-Acting on climate change and energy security", Journal of Power Sources, Cilt 157, No.2, 2006, s.893-901.

Brzezinski, Zbigniew. "A Geostrategy for Eurasia", Foreign Affairs, Cilt 76, No.5, Eylül/Ekim 1997, s.50-64.

Brzezinski, Zbigniew. The Grand Chessboard: American Primacy and Its Geostrategic Imperatives, New York, Basic Books, 1997.

Broda-Bahm, T.Kenneth. "Finding Protection in Definitions: The Quest for Environmental Security", Argumentation and Advocacy, Cilt 5, No.4, 1999, s.59-70.

Bruntland, Gro Harlem (der). Our Common Future, The World Commission on Environment and Development, Oxford, Oxford University Press, 1987.

"Bureau of Energy Sources", http://www.state.gov/e/enr/, (Erişim Tarihi 16 Ocak 2016).

Busby, Joshua W. "Climate Change Blues: Why the United States and Europe Just Can't Get Along”, Current History, Mart 2003, s.113-118.

Busby, Joshua W. "Climate Change and National Security: An Agenda for Action", Council of Foreign Relations (CFR), No.32, November 2007, s.4-32.

Cassidy, Peter ve Mark Raymont. "Has the Kyoto Protocol Got a Future without the USA?", Refocus, Cilt 2, No.5, Haziran 2001, s.28-29.

Cohen, Saul B. Geopolitics: The Geography of International Relations, İngiltere, Rowman \& Littlefield, 2015.

"Compagnie nationale des mines de France", 26 Ocak 2015, https://fr.wikipedia.org/wiki/Compagnie_ nationale_des_mines_de_France, (Erişim Tarihi 22 Şubat 2016).

Cook, Benjamin I. et.al. "Spatiotemporal Drought Variability in the Mediterranean over the Last 900 Years, Journal Of Geophysical Research: Atmospheres, Cilt 121, No.5, 2016, s.2060-2074.

“COP 21", https://unfccc.int/meetings/paris_nov_2015/session/9057.php, (Erişim Tarihi 23 Şubat 2016).

“COP21, CMP11”, http://www.cop21.gouv.fr/en/, (Erişim Tarihi 23 Şubat 2016).

Dalby, Simon. "Environmental Insecurities: Geopolitics, Resources and Conflict”, Economic and Political Weekly, Cilt 38, No.48, 2003, s.5073-5079.

Dalby, Simon. "The Geopolitics of Climate Change”, Political Geography, Cilt 37, Kasım 2013, s.38-47.

Ebinger, Charles K. ve Evie Zambetakis. "The Geopolitics of Arctic Melt”, Bernice Lee (der), Tackling Resource Challenges in the 21st Century: Avoiding Worst Case Scenarios, Blackwell Publishing Ltd./The Royal Institute of International Affairs, 2009, s.1215-1232.

Ecclestone, Christopher. "German Resource Alliance: The Rohstoff Allianz 'Circles the Wagons' to Make Investments”, 21 Mayls 2015, http://investorintel.com/technology-metals-intel/german-circlingwagons/, (Erişim Tarihi 21 Ocak 2016).

Ediger, Volkan Ş. "Enerji Arz Güvenliği ve Ulusal Güvenlik Arasındaki İlişki”, Enerji Arz Güvenliği, Ankara, SAREM Yayınları, 2007, s.1-47.

Ediger, Volkan Ş. "Energy Transition Periods: Lessons Learnt from the Past", Abu Dabi, The Emirates Center for Strategic Studies and Research (ECSSR) Publications, 2011, s.175-202.

Ediger, Volkan Ş. Enerjide Yeni Dünya Düzeni ve Türkiye, Akademi Forumu No.67, Türkiye Bilimler Akademisi (TÜBA) Yayınları, Ankara, 2011.

Ediger, Volkan Ş. (der). Türkiye’de İklim Değişikliği ve Sürdürülebilir Enerji, İstanbul, ENIVA Yayınları, 2013. 
Ediger, Volkan Ş. TKİ ve Kömürün Tarihçesi ile Kömür Stratejileri, Ankara, TKİ Kurumu Yayınları, 2. Baskı, 2015. Erdoğdu, Erkan. "Turkish Support to Kyoto Protocol: A Reality or Just an Illusion”, Renewable and Sustainable Energy Reviews, Cilt 14, No.3, Nisan 2010, s.1111-1117.

Freedman, Lawrence. "Order and Disorder in the New World", Foreign Affairs, Cilt 71, No.1, 1991, s.20-37.

Frei, Christoph W. "The Kyoto Protocol-A Victim of Supply Security? or: If Maslow were in Energy Politics”, Energy Policy, Cilt 32, No.11, 2004, s.1253-1256.

Grevi, Giovanni. The Interpolar World: A New Scenario, Paris, European Union Institute for Security Studies, Haziran 2009, s.1-39.

Haass, Richard N. "The Age of Nonpolarity: What Will Follow U.S. Dominance”, Foreign Affairs, Cilt 87, No.3, Mayıs/Haziran 2008, s.44-56.

Hovi, Jon ve CICERO.” Towards a Better Compliance System for the Climate Regime?", Chistopher P. Vasser (der), The Koyoto Protocol: Economic Assessments, Implemetation Mechanisms and Policy Implications, New York, Nova Science Publishers, Inc., 2009.

Hubbert, M.C. King. "Nuclear Energy and the Fossil Fuels", Drilling and Production Practice, American Petroleum Institute, No.95, 1956, s.7-25.

Hubbert, M.C. King. “Techniques of Prediction with Application to the Petroleum Industry”, Proceedings of the $44^{\text {th }}$ Annual Meeting of the American Association of Petroleum Geologists, Dallas, AAPG Bulletin, Cilt 43, No.7, 1959, s. 1767-1768.

Huntington, Hillard G. ve Stephen P. A. Brown. "Energy Security and Global Climate Change Mitigation", Energy Policy, Cilt 32, No.6, 2004, s.715-718.

Huntington, Samuel P. “The Clash of Civilizations?”, Foreign Affairs, Cilt 72, No.3, 1993, s.22-49.

“IPCC Fourth Assessment Report: Climate Change 2007", https://www.ipcc.ch/publications_and_data/ar4/ wg2/en/annexessglossary-a-d.html, (Erişim Tarihi 17 Şubat 2016).

Kaplan, Robert D. “The Geopolitics of Shale”, 19 Aralık 2012, http://www.businessforum.com/STRATFOR_ Geopolitics-Shale.pdf, (Erişim Tarihi 16 Şubat 2016).

Kaplan, Robert D. "The Geopolitics of Energy”, 2 Nisan 2014, http://www.ctcitraining.org/topdocs/ GeopoliticsEnergy.pdf, (Erişim Tarihi 03 Mart 2016).

Kahn, Matthew E. “The Geopolitics of Climate Change: An Economist's Perspective”, Political Geography, Cilt 37, Kasim 2013, s.53-55.

Klare, Michael. "The New Geopolitics of Energy”, The Nation, 19 Mayıs 2008, s.1-8.

"KyotoProtocol", http://unfccc.int/kyoto_protocol/items/2830.php ve http://unfccc.int/kyoto_protocol/ mechanisms/items/2998.php, (Erişim Tarihi 13 Şubat 2016).

Lewis, Bernard. "Rethinking the Middle East", Foreign Affairs, Cilt 71, No.4, Sonbahar 1992, s.99-118.

Lewis, Bernard. "The West and the Middle East”, Foreign Affairs, Cilt 76, No.1, Ocak/Şubat 1997, s.114-130.

Mañé-Estrada, Aurèlia. "European Energy Security: Towards the Creation of the Geo-Energy Space”, Energy Policy, Cilt 34, No.18, 2006, s.3773-3786.

Mannea, Alan ve Richard Richels. "US Rejection of the Kyoto Protocol: The Impact on Compliance Costs and $\mathrm{CO}_{2}$ Emissions”, Energy Policy, Cilt 32, No.4, 2004, s.447-454.

Marsh, David. "France goes back to mining as source of national wealth", 24 Şubat 2014, http://www. marketwatch.com/story/france-goes-back-to-mining-as-source-of-national-wealth-2014-02-24, (Erişim Tarihi 21 Ocak 2016).

Maslow, Abraham. "A Theory of Human Motivation", Psychological Review, Cilt 50, No.4, 1943, s.370-396.

Meadows, Donella H. et.al. Limits to Growth, Universe Book, 1972.

"Mitigation and Adaptation", http://climate.nasa.gov/solutions/adaptation-mitigation/, (Erişim Tarihi 23 Ocak 2016). 
Siche, J.R. et.al. "Sustainability of Nations by Indices: Comparative Study Between Environmental Sustainability Index, Ecological Footprint and the Energy Performance Indices”, Ecological Economics, Cilt 66, No.4, 2008, s.628-637.

"Statistical Review of World Energy 2015", http://www.bp.com/statisticalreview, (Erişim Tarihi 11 Ocak 2016).

Stocker, Thomas F. et.al. Climate Change 2013, The Physical Science Basis, Working Group I: Contribution to the Fifth Assessment Report of the Intergovernmental Panel on Climate Change, New York, Cambridge University Press, 2013.

Study on Energy Supply Security and Geopolitics, Hague, CIEP, Ocak 2004.

“The Archive, 1970-2000.”, http://www.theecologist.info/page33.html, (Erişim Tarihi 09 Ocak 2016).

“The EU Emissions Trading System (EUETS)",http://ec.europa.eu/clima/policies/ets/index_en.htm, (Erişim Tarihi 22 Şubat 2016).

“The Rise of State Capitalism”, 21 Ocak 2012, http://www.economist.com/node/21543160, (Erişim Tarihi 16 Ocak 2016).

Thölken, Hinrich. "Politics and Policies", British Medical Journal, Cilt 344, No.7849, 24 Mart 2012, s.33-34.

Tonnesson, Stein. "The Case for a Proactive Indian and Chinese Approach to Climate Change and Energy Security", Strategic Analysis, Cilt 31, No.3, Mayıs 2007, s.417-445.

Vasser, Chistopher P. (der). The Koyoto Protocol: Economic Assessments, Implemetation Mechanisms and Policy Implications, New York, Nova Science Publishers, Inc., 2009.

Wright, Robin. "Islam, Democracy and the West", Foreign Affairs, Cilt 72, No.3, Yaz 1992, s.131-145. 